\title{
The physical processes causing nocturnal rainfall over northwest Australia and their representation in high- and low-resolution models with parametrized convection
} DOI:

10.1002/qj.3223

\section{Document Version \\ Accepted author manuscript}

Link to publication record in Manchester Research Explorer

Citation for published version (APA):

Ackerley, D., Birch, C. E., Garcia-Carreras, L., Lavender, S. L., \& Weller, E. (2018). The physical processes causing nocturnal rainfall over northwest Australia and their representation in high- and low-resolution models with parametrized convection. Quarterly Journal of the Royal Meteorological Society, 144(711), 511-528. https://doi.org/10.1002/qj.3223

\section{Published in:}

Quarterly Journal of the Royal Meteorological Society

\section{Citing this paper}

Please note that where the full-text provided on Manchester Research Explorer is the Author Accepted Manuscript or Proof version this may differ from the final Published version. If citing, it is advised that you check and use the publisher's definitive version.

\section{General rights}

Copyright and moral rights for the publications made accessible in the Research Explorer are retained by the authors and/or other copyright owners and it is a condition of accessing publications that users recognise and abide by the legal requirements associated with these rights.

\section{Takedown policy}

If you believe that this document breaches copyright please refer to the University of Manchester's Takedown Procedures [http://man.ac.uk/04Y6Bo] or contact uml.scholarlycommunications@manchester.ac.uk providing relevant details, so we can investigate your claim.

\section{OPEN ACCESS}




\title{
The physical processes that cause nocturnal rainfall over north-west Australia and their representation in high- and low-resolution models with parametrized convection
}

\author{
D. Ackerley ${ }^{\mathrm{a} *}$, C. E. Birch ${ }^{\mathrm{b}, \mathrm{c}}$, L. Garcia-Carreras ${ }^{\mathrm{b}}$, S. L. Lavender ${ }^{\mathrm{d}}$ and E. Weller ${ }^{\mathrm{a}}$ \\ ${ }^{\mathrm{a}}$ ARC Centre of Excellence for Climate System Science, School of Earth Atmosphere and Environment, Monash University, Victoria \\ 3800, Australia \\ ${ }^{\mathrm{b}}$ School of Earth and Environment, University of Leeds, Leeds, U.K. \\ ${ }^{\mathrm{c}}$ MetOffice@Leeds, University of Leeds, Leeds, U.K. \\ ${ }^{\mathrm{d}}$ CSIRO Climate Science Centre, Aspendale, Victoria, Australia \\ *Correspondence to: duncan.ackerley@ monash.edu
}

The diurnal cycle of precipitation in the tropics is represented poorly in general circulation models (GCMs), which is primarily attributed to the representation of moist convection. Nonetheless, in areas where precipitation is driven by the diurnal cycle in the synoptic-scale flow, GCMs may represent that circulation-rainfall relationship well. Over north-west Australia there is a tendency for precipitation to peak overnight where the diurnal cycle of the heat low circulation leads to the development of strong convergence after local sunset. In order to assess the heat low-precipitation relationship in more detail, a case study approach is used to investigate the actual "weather" that is responsible for nighttime precipitation. The study shows that, where there is sufficient moisture, precipitation typically forms along convergence zones that coincide with boundaries between relatively moist and dry air masses (termed a "dryline"). A convergence line detection algorithm is then used to identify the fraction of observed nocturnal rainfall that is associated with any convergence zones. The same evaluation is then undertaken for a relatively high (MetUM) and low-resolution (ACCESS1.0) GCM, which simulate similar rainfall-generation processes to the observations. Finally, the convergence line detection/precipitation algorithm is run on other GCM data (from CMIP5) to see whether the same processes occur despite different model configurations (i.e. physics), which appears to be the case.

Key Words: nocturnal, rainfall, convergence, dryline, heat low, CMIP5, MetUM, north-west Australia 


\section{Introduction and aims}

Within the tropics and sub-tropics, precipitation maxima tend to occur in the mid-to-late afternoon (Yang and Smith 2006). Despite a good understanding of the physical processes that cause the midafternoon peak in rainfall, General Circulation Models (GCMs) simulate the timing (and intensity) of the rainfall maximum poorly (Yang and Slingo 2001; Dai 2006; Dirmeyer et al. 2012). The poor representation of daytime, tropical precipitation in GCMs is primarily caused by the parametrization of convection (Betts and Jakob2002a,b; Dai 2006; Neale and Slingo 2003; Stratton and Stirling 2012; Yang and Slingo 2001). Nevertheless, where tropical and sub-tropical precipitation maxima are not driven by daytime solar heating (such as over north-west Australia, see Berry et al. 2011), GCMs may be able to simulate the processes that cause rainfall correctly.

The development of a heat low over north-west Australia during the austral summer (December, January, February-from now, DJF) is important in causing precipitation to occur after sunset (Berry et al. 2011). The development of the nocturnal boundary layer reduces the low-level friction, which allows air parcels to accelerate down-gradient and converge (the process is discussed in more detail in Racz and Smith 1999; Spengler et al. 2005; Spengler and Smith 2008). This continental-scale reorganisation of the heat low circulation is actually represented well in lowresolution GCMs, and there is evidence that the associated nocturnal convergence initiates precipitation (see Ackerley et al. 2014, 2015). Nevertheless, the actual "weather" processes that occur on sub-daily timescales are not investigated in the observational study of Berry et al. (2011) or the GCM studies of Ackerley et al. (2014, 2015), who both use composite averages to infer the precipitation-circulation relationship. Therefore, in order to properly identify whether the nocturnal precipitation is simulated correctly in the models, an understanding of the physical processes that occur on sub-daily time scales is required.

The daily-to-sub-daily atmospheric processes that cause nocturnal precipitation in the real world and a selection of GCMs is presented in this study. Using a combination of case studies and composites (climatologies), the aims of this paper are to: (i) Investigate the role of the north-west Australian heat low in the formation of nocturnal convergence and precipitation;

(ii) Identify how the diurnal (sub-daily) reorganisation of the flow around the heat low acts to initiate or maintain precipitation after sunset;

(iii) Identify where that precipitation forms in relation to the heat low centre;

(iv) Investigate whether GCMs can also represent the same physical processes and also simulate nocturnal rainfall for the right reasons.

As parametrized convection is used extensively in atmospheric modelling (and in simulations of future climate), this study focuses only on such models. This study does not address the errors in the simulated daytime precipitation as the reasons for such errors are documented elsewhere (Betts and Jakob 2002a,b; Dai 2006; Neale and Slingo 2003; Stratton and Stirling 2012; Yang and Slingo 2001).

This paper explores the resolution dependence of GCMsimulated nocturnal rainfall by using relatively high (approximately 12 km grid spaced Met Office Unified Model-MetUM) and low resolution $(\sim 100 \mathrm{~km}$ grid spaced Australian Community Climate and Earth System Simulator-ACCESS) model simulations. The study is then extended to a selection of GCMs from the Fifth Coupled Model Intercomparison Project (CMIP5) to evaluate whether the processes that cause nocturnal rainfall are model dependent or not, which is an approach that is also undertaken in Vellinga et al. (2016). If the sub-daily, nocturnal rain-generating processes are modelled correctly, then such mechanisms may also be correct in (for example) climate change projections. Moreover, if the GCMs simulate the processes well over north-west Australia they may also do well in other regions of the globe (e.g. the West African monsoon surge and the low-level nocturnal jet over North America, see Parker et al. 2005; Dai et al. 1999, respectively). Nevertheless, the impact of future climate change on nocturnal rainfall and expanding the analysis beyond north-west Australia are beyond the scope of this study, and remain a subject for future work.

Section 2 outlines the data and methods used in this study. Section 3 describes the physical processes that cause nocturnal precipitation over north-west Australia. An evaluation 
of these processes in high-resolution and low-resolution GCMs is presented in Sections 4 and 5, respectively. A selection of CMIP5 models are assessed in Section 6 to identify whether other GCMs can represent the same physical processes described in Sections 3 -5. The final discussion and conclusions are given in Section 7. There is also a significant supplementary material section where other case studies are presented from the analysis in Sections 3, 4 and 5, which provides further evidence to validate our hypotheses.

\section{Data and models}

\subsection{Datasets}

\subsubsection{Reanalysis}

The dynamical and thermodynamical properties of the atmosphere (zonal and meridional flow, mean sea level pressure, specific humidity and air temperature) from the European Centre for Medium-Range Weather Forecasts Interim Reanalysis (ECMWF ERA-Interim, Dee et al. 2011, from now ERA-Interim) are used to understand the physical processes that cause nocturnal rainfall over north-west Australia. Data are taken from the ERA-Interim archive for each DJF from 1979/80-2012/13. The 6-hourly data are available at 0800, 1400, 2000 and 0200 Australian Western Standard Time (AWST, UTC+8 hours). The ERA-Interim data are used to make composites of the diurnal circulation over the Australian continent for the 34 DJFs available (Section 3.1) and, to identify heat low centres associated with the specific case study given in Section 3.2.

In order to better identify the weather features (e.g. convergence zones) that are important for the development of nocturnal precipitation, this study also uses the high-resolution $(25 \mathrm{~km}$ grid spacing) ECMWF-YOTC (Year Of Tropical Convection Moncrieff et al. 2012) temperature, circulation and moisture content dataset. The ECMWF-YOTC (from now YOTC) data are available from May 2008-April 2010, which provides a relatively narrow time frame (only 2 years) from which to identify nocturnal rainfall events. Nevertheless, several cases where precipitation increases or is initiated overnight are identified during the twoyear period. For brevity, only one case on $10^{t h}-11^{t h}$ January 2010 is discussed in the main text; however, two other cases are presented $\left(11^{t h}-12^{t h}\right.$ and $12^{t h}-13^{t h}$ January 2010) in the supplementary material (Sections S1.1 and S1.2) as further evidence. The YOTC data therefore, provide more detail (i.e. higher resolution) on the specific case study described in Section 3.2 .

While reanalysis data are not observations and may have significant biases in areas with a sparse observational network (e.g. subSaharan Africa see, Garcia-Carreras et al. 2013; Roberts et al. 2015), over north-west Australia there are numerous surface observations with which to constrain the model ${ }^{*}$. The reanalysis data provide a 6-hourly, instantaneous measure of the state of the atmosphere. The YOTC and ERA-Interim meridional, zonal and vertical winds, and specific humidity (all taken on pressure levels e.g. $925 \mathrm{hPa}$ ) are used in this study

\subsubsection{Precipitation}

In order to assess the processes leading to nocturnal rainfall over north-west Australia, 3-hourly rainfall from the CPC morphing method (CMORPH) dataset (Joyce et al. 2004) are used for the period 1998-2014. The gridded CMORPH data have a latitude-longitude spacing of $0.25^{\circ} \times 0.25^{\circ}$ between $\pm 60^{\circ}$ (latitude). Consecutive 3-hourly CMORPH data are summed to give accumulations \pm 3 hours of the reanalysis data times (i.e. 0500-1100, 1100-1700, 1700-2300 and 2300-0500 AWST). Given that the reanalysis data provide a 6-hourly instantaneous "snapshot" of the atmosphere, but the precipitation dataset used is an accumulation \pm 3 hours of the analysis times, an exact co-location of important circulation features (e.g. convergence zones) with the analysed precipitation should not be expected. The CMORPH data are used to produce composites of the diurnal cycle in precipitation over Australia over all available DJFs (16 years, Section 3.1) and to identify the location of precipitation in the case study (Section 3.2).

The main limitation of the CMORPH data is associated with the satellite-derived maximum in rainfall being later that that of rain gauge estimates (Dai et al. 2007). Nevertheless, Ackerley et al. (2014) showed that the timing of the CMORPH-derived precipitation maximum over north-west Australia agrees well with surface-based pluviograph measurements from Berry et al. (2011). Therefore the 6-hourly CMORPH estimates are unlikely

${ }^{*}$ see http ://www.bom.gov.au/wa/observations/map.shtml 
to be affected by the delay in peak rainfall described by Dai et al. (2007).

\subsection{Models}

\subsubsection{MetUM with $12 \mathrm{~km}$ grid spacing (Parl2k)}

A global, high-resolution $\left(0.175^{\circ}\right.$ longitude by $0.117^{\circ}$ latitude, equivalent to $12 \mathrm{~km}$ grid spacing at mid-latitudes) Global Atmosphere/Global Land (GA4, Walters et al. 2014) version of the Met Office Unified Model (MetUM) is used in this study (and referred to throughout as Par12k). Finer details of the experimental setup and model parametrizations are given in Birch et al. (2015) and Walters et al. (2014). Pertinent to this study is the representation of convection within the model, which is parametrized (Gregory and Rowntree 1990) and the same scheme is used by the low-resolution GCM (ACCESS) described below.

The model uses prescribed (daily) sea surface temperatures and sea ice concentrations from Operational Sea Surface Temperature and Sea Ice Analysis (OSTIA, Donlon et al. 2012) dataset. The model was initialised in March 2008 in a "free-running" mode (i.e. no data assimilation). DJF data are taken from a three year period (2008-09, 2009-10 and 2010-11) for use in this analysis. While the SST field is representative of the observed state during 2008-2011, the actual weather systems will not match those that actually occurred between these dates. Therefore, the reference to specific dates is somewhat arbitrary and serves only for ease of viewing for the reader. Composites of circulation and precipitation are made for all three DJFs (Section 4.1) and the circulation and precipitation associated with the specific case study are described in Section 4.2. For brevity, only one case on $16^{\text {th }}-17^{\text {th }}$ January 2010 is discussed in the main text for Par12k; however, two other cases are presented $\left(17^{t h}-18^{t h}\right.$ and $18^{t h}-19^{\text {th }}$ January 2010) in the supplementary material (Sections S2.1 and S2.2) as further evidence.

\subsubsection{ACCESS1.0}

The atmosphere-only component of the Australian Community Climate and Earth System Simulator version 1.0 (ACCESS1.0) is used in this study and is very similar to the HadGEM2(r1.1) version of the MetUM (Hewitt et al. 2011; Martin et al. 2011). The version of ACCESS1.0 used here comprises 38 vertical levels and has a grid spacing of $1.875^{\circ}$ longitude by $1.25^{\circ}$ latitude ( $150 \mathrm{~km}$ grid spacing; see Allcock and Ackerley 2016, for more details). Parametrized physical processes within the model include radiation, surface energy exchange, precipitation, clouds and convection. For a more detailed discussion of the ACCESS1.0 configuration see Bi et al. (2013). Despite ACCESS1.0 comprising an older configuration of the MetUM than Par12k, the compatibility of the convection schemes (ACCESS1.0 also uses the Gregory and Rowntree 1990, scheme) provides a platform from which to compare a lower (ACCESS1.0) and higher (Par12k) resolution model more directly. Furthermore, as ACCESS1.0 is one of the models used in the Fifth Coupled Model Intercomparison Project (CMIP5), the analyses used to compare Par12k with ACCESS1.0 can then be extended into the CMIP5 models too (see below).

The ACCESS1.0 simulation is run from $1^{\text {st }}$ January 1978 to $1^{\text {st }}$ March 2001 with prescribed monthly sea surface temperatures (SSTs) and sea ice conditions as per the specifications of an "Atmosphere Model Intercomparison Project" (AMIP) experiment (Gates 1992; Gates et al. 1999; Taylor et al. 2000), whereby monthly SST and sea ice are interpolated and updated daily. The first eleven months (January-November 1978) are disregarded to allow for the model to "spin-up" then each subsequent DJF (1979-2001) is considered for the analysis below (Section 5). Again (as with Par12k), while the SST field is representative of the period 1979-2001, the actual weather systems will not match those that actually occurred on those specific dates (and those of the presented case studiessee Section 5.2). Therefore, the reference to specific dates is somewhat arbitrary and serves only for ease of viewing for the reader. Composites of circulation and precipitation are made for all 21 DJFs (Section 5.1) and the circulation and precipitation associated with the specific case study are described in Section 5.2. For brevity, only one case on $8^{t h}-9^{t h}$ February 1983 is discussed in the main text for ACCESS1.0; however, two other cases are presented $\left(9^{t h}-10^{t h}\right.$ and $10^{t h}-11^{t h}$ February 1983) in the supplementary material (Sections S3.1 and S3.2) as further evidence. 


\subsubsection{CMIP5 models}

The models used in this study, their horizontal and vertical resolutions, and their relevant references are listed in Table 1. Nine different model simulations were chosen and are identical to those used in Ackerley et al. (2015). Data are taken from the AMIP simulations from the fifth Coupled Model Intercomparison Project (CMIP5, Taylor et al. 2012). The AMIP simulations are used here to extend the analysis presented in Ackerley et al. (2015) by applying the convergence line algorithm, described in Section 2.4 below, to the 2000 AWST and 0200 AWST $925 \mathrm{hPa}$ circulation and precipitation (all DJFs from 1979/80-2007/08, 29 years). A more in-depth discussion of the models used in this study (and their biases) are presented in Ackerley et al. (2015), which the reader is referred to for more details. Here, the focus is on the nocturnal (2000 and 0200 AWST) circulation and precipitation only (see Section 6).

\subsection{Heat low detection}

Heat lows are detected in the 6-hourly ERA-Interim reanalysis, and the Par12k and ACCESS1.0 model data, using the method described by Lavender (2017). This detection algorithm analyses regions that exceed the daily $90^{t h}$ percentile threshold of 850 $\mathrm{hPa}$ potential temperature for low pressure systems with heat low characteristics. To be defined as a heat low the mean sea-level pressure must be a minimum relative to surrounding grid points and there must be a cyclonic circulation at $850 \mathrm{hPa}$ and an anticyclonic circulation aloft $(500 \mathrm{hPa})$. Due to the limited time period of the case studies (i.e. one full 24-hour period), no tracking of the systems is done in the present study.

\subsection{Convergence line/zone identification}

Horizontal wind fields from reanalysis and climate model data sets are examined using the objective instantaneous convergence line identification method described in detail by Weller et al. (2017), which is a modified version of that developed by Berry and Reeder (2014). Convergence line points are identified as locations of minima in the divergence field, and a line-joining algorithm is used to link the points into organised convergence lines. In the current study, the method is applied to 6-hourly divergence fields calculated at $925 \mathrm{hPa}$.
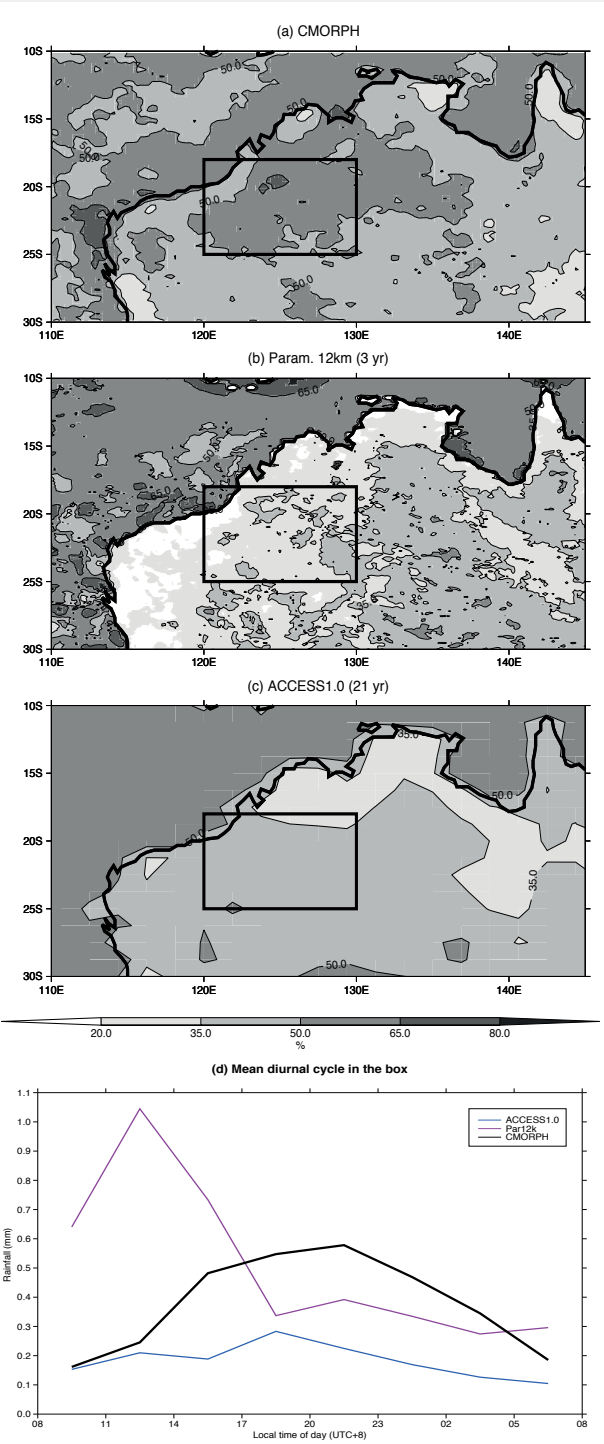

Figure 1. The mean contribution (\%) of nocturnal (2000-0800 AWST) rainfall to the daily total (0800-0800 AWST) from (a) CMORPH, (b) Par12k and, (c)

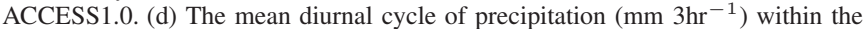
boxed region $\left(120^{\circ} \mathrm{E}-130^{\circ} \mathrm{E}\right.$ and $\left.18^{\circ} \mathrm{S}-25^{\circ} \mathrm{S}\right)$ in Figs. 1(a)-(c) for CMORPH (black line), Par12k (purple line) and ACCESS1.0 (blue line).

To examine precipitation associated with convergence lines, the same technique described in Weller et al. (2017) is employed. Precipitation is associated with objectively identified convergence lines when they are found to occur within close proximity to each other for each 6-hourly field. In the current study, a surrounding box ( \pm 1 grid point in size) is searched for the existence of an identified convergence line for each rain grid point. The search accounts for any rainfall that may be related to a broader, synopticscale system that is associated with any such convergence line.

In this paper the terms "convergence line" and "convergence zone" are considered to be equivalent and are used interchangeably. 
Table 1. The CMIP5 models, their horizontal grid spacing and number of vertical levels, and the relevant references.

\begin{tabular}{|c|c|c|}
\hline Model & $\begin{array}{c}\text { Resolution } \\
\text { [horizontal] (vertical) }\end{array}$ & References \\
\hline ACCESS 1.3 & {$\left[\mathrm{~N} 96,1.875^{\circ} \times 1.25^{\circ}\right](38$ levels $)$} & $\begin{array}{c}\text { Hewitt et al. (2011); Bi et al. (2013) } \\
\text { Kowalczyk et al. (2013) }\end{array}$ \\
\hline BCC-CSM1-1 & {$\left[\mathrm{T} 42,2.81^{\circ}\right](26$ levels $)$} & Wu et al. (2010); Xin et al. (2013) \\
\hline BCC-CSM1-1-m & {$\left[\mathrm{T} 160,1.0^{\circ}\right]$ (26 levels) } & Wu et al. (2010); Xin et al. (2013) \\
\hline BNU-ESM & {$\left[\mathrm{T} 42,2.81^{\circ}\right]$ (26 levels) } & Ji et al. (2014) \\
\hline CCSM4 & {$\left[1.25^{\circ} \times 0.9^{\circ}\right](26$ levels $)$} & Gent et al. (2011) \\
\hline IPSL-CM5A-LR & {$\left[3.75^{\circ} \times 1.875^{\circ}\right]$ (39 levels) } & Dufresne et al. (2013) \\
\hline MIROC5 & {$\left[\mathrm{T} 85,1.4^{\circ}\right]$ (40 levels) } & Watanabe et al. (2010) \\
\hline MRI-CGCM3 & {$\left[\mathrm{T} 159,1.125^{\circ}\right]$ (48 levels) } & Yukimoto et al. (2012) \\
\hline NorESM1-M & {$\left[2.5^{\circ} \times 1.9^{\circ}\right](26$ levels $)$} & Bentsen et al. (2013) \\
\hline
\end{tabular}

\section{Observations: Climatology and case study}

\subsection{Mean diurnal circulation and nocturnal rainfall}

Previous work (Berry etal. 2011) has shown that there is a tendency for the majority of precipitation over north-west Australia to happen overnight. The fraction of DJF precipitation that occurs between 2000 AWST and 0800 AWST from CMORPH (averaged across 1998-2014) confirms this (Figure 1(a)), with a broad region over the north-west of the continent (from approximately $120^{\circ} \mathrm{E}-135^{\circ} \mathrm{E}$ and $17.5^{\circ} \mathrm{S}-25^{\circ} \mathrm{S}$ ) where $>50 \%$ of the DJF precipitation occurs overnight.

Over north-west Australia, sunset occurs between 1800-1900 AWST and sunrise between 0500-0600 AWST during DJF, therefore surface solar heating cannot act to destabilise the low-level air and cause moist convection between these times. Ackerley et al. (2014) and Berry et al. (2011) show that the diurnal cycle of the heat low circulation can cause the necessary convergence to initiate nocturnal precipitation. This is illustrated in Figures 2(a)-(d), which show the mean diurnal cycle of the $925 \mathrm{hPa}$ flow from ERA-Interim. At 0800 AWST there is predominantly easterly flow over the continent with cyclonic flow over the north-west (Figure 2(a)). The cyclonic flow is associated with the climatological location of the continental heat low in DJF (Lavender 2017). The $925 \mathrm{hPa}$ flow weakens at 1400 AWST relative to 0800 AWST (Figure 2(b)) from the increase in low-level drag caused by surface heating and dry convection (turbulence). By 2000 AWST the nocturnal boundary layer forms as the surface cools, which reduces the low-level friction and the flow accelerates down the pressure gradient into the low centre and converges (grey shading, Figure 2(c)). The flow then turns anticyclonically at 0200 AWST relative to 2000 AWST and the convergence weakens as the flow tends towards geostrophic balance. This reorganization of the flow is a well-known feature of the circulation around heat lows over relatively flat terrain (Racz and Smith 1999; Spengler et al. 2005; Spengler and Smith 2008).

The region of strong nocturnal convergence between 20000800 AWST corresponds with the region where $>50 \%$ of the precipitation occurs at night (compare Figures 1(a) and, 2(c) and (d)). Berry et al. (2011) however, show that the nocturnal convergence alone is not sufficient to cause precipitation and a synoptic-scale change in the circulation from dry southeasterlies to relatively moist northeasterlies is required to provide the necessary water for precipitation to occur. Berry et al. (2011) make composites of the circulation on days with and without rainfall to show the mean change in the synoptic-scale circulation that is responsible for causing rainfall over north-west Australia. As the aim in this study is to identify the specific processes responsible for nocturnal precipitation at weather time scales (i.e. sub-daily to daily) it is therefore useful to look at a case study instead of a composite. Such a case study should illustrate how, and why, the reorganisation of the heat low circulation causes or enhances rainfall overnight. Furthermore, the case study should elucidate why convergence alone is not the governing factor for nocturnal precipitation.

\subsection{Case study}

In order to identify how the reorganisation of the heat low circulation actually initiates or enhances precipitation after sunset, a specific case is considered when such a sequence of 
(a) ERA-Interim 0800 AWST

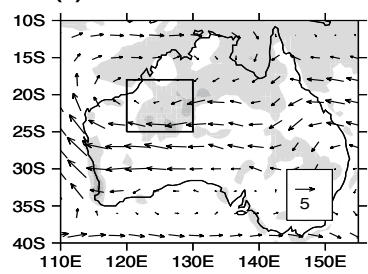

(e) Par12k 0800 AWST

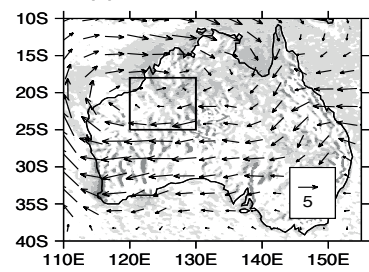

(i) ACCESS1.0 0800 AWST

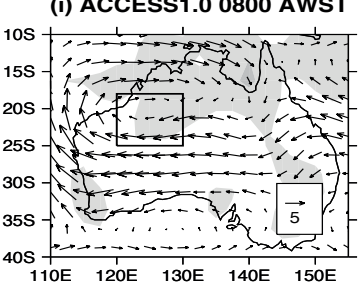

(b) ERA-Interim 1400 AWST

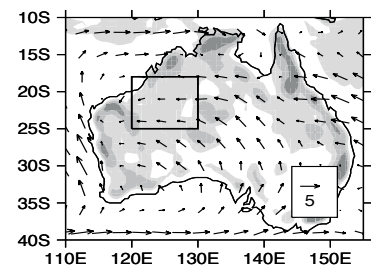

(f) Par12k 1400 AWST

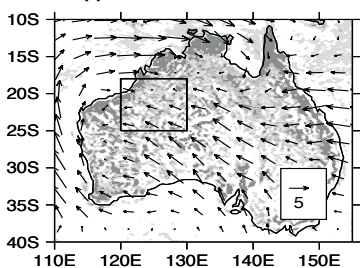

(j) ACCESS1.0 1400 AWST

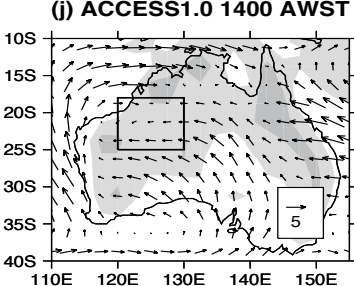

(c) ERA-Interim 2000 AWST

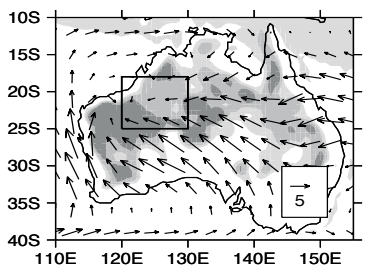

(g) Par12k 2000 AWST

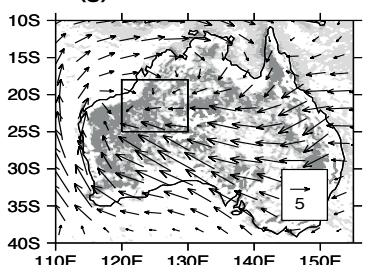

(k) ACCESS1.0 2000 AWST

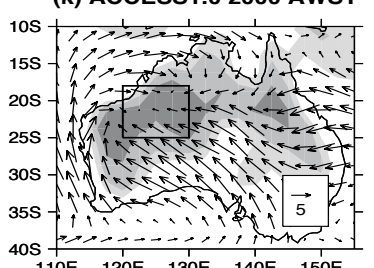

(d) ERA-Interim 0200 AWST

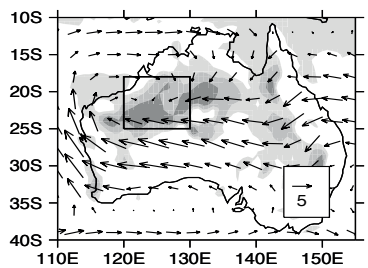

(h) Par12k 0200 AWST

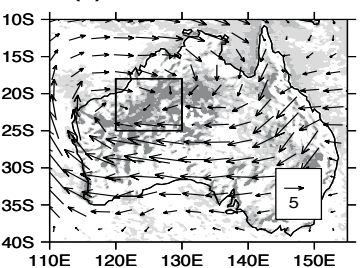

(I) ACCESS1.0 0200 AWST

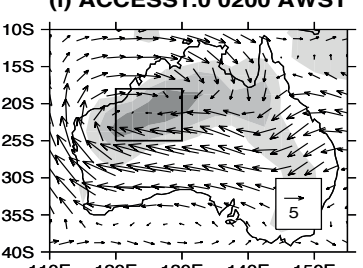

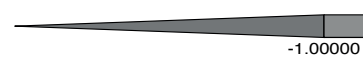

$-1.00000 \mathrm{e}-05$

Divergence $\left(\mathrm{s}^{-1}\right)$

Figure 2. Composited ERA-Interim (1979/80-2012/13) DJF 925 hPa flow (vectors, $\mathrm{m} \mathrm{s}^{-1}$ ) and negative divergence (i.e. convergence, $\mathrm{s}^{-1}$ ) (a) 0800 AWST, (b) 1400 AWST, (c) 2000 AWST and (d) 0200 AWST. The same circulation fields are shown for corresponding times in (e)-(h) for Par12k and in (i)-(1) for ACCESS1.0.

events occurs (i.e. nocturnal convergence and precipitation). For brevity, only one case is considered; however, an inspection of other nocturnal precipitation cases (not shown) display similar processes at work. We identified a period of increased nocturnal rainfall in the CMORPH dataset that occurred from the $10^{\text {th }}$ to $13^{t h}$ January 2010; however, only the first day $\left(10^{t h}-11^{t h}\right)$ of the event is considered here. The salient features of the other two days are given in the supplementary material (S1.1 and $\mathrm{S} 1.2)$ to provide further supporting evidence.

Heat low centres are identified using the algorithm described in Section 2.3 to separate them from other synoptic depressions (such as monsoon lows or tropical cyclones). Given the importance of the heat low for the diurnal variation of the lowlevel flow (discussed in Section 3.1), the detection algorithm allows us to identify whether one is present during the case study. The detection algorithm is run on the 6-hourly YOTC data, which results in the multiple heat low centre detections plotted in Figure 3. A diurnal variation in the structure of near-stationary heat lows, and hence location of the detected minimum pressure (as well as some movement of non-stationary lows), accounts for the multiple detections throughout the day. The detections therefore, show the broad location of any heat low on a given day.
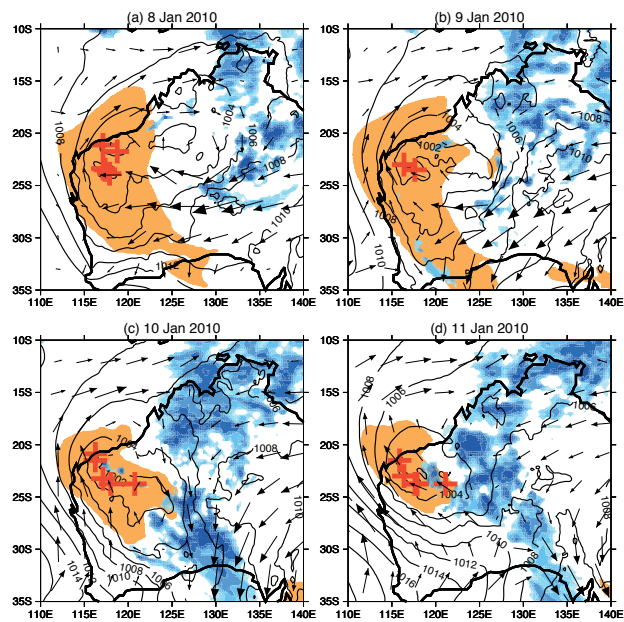

Figure 3. ERA-Interim case study analysis of mean sea level pressure, hPa (solid lines), $850 \mathrm{hPa}$ winds, $\mathrm{m} \mathrm{s}^{-1}$ (arrows), daily rainfall $>2 \mathrm{~mm}$ (blue shading), 850 $\mathrm{hPa}$ potential temperature $\geq 312 \mathrm{~K}$ (amber shading) and identified heat low centres (+ in the figure) from the detection algorithm described in Section 2.3 (all 6-hourly detections are included in each daily plot) for (a) $8^{\text {th }}$ January 2010, (b) $9^{\text {th }}$ January 2010, (c) $10^{t h}$ January 2010 and (d) $11^{t h}$ January 2010.

On $8^{\text {th }}-9^{\text {th }}$ January 2010, there is a heat low located around $117^{\circ} \mathrm{E}$ and $22^{\circ} \mathrm{S}$ as indicated by the co-located amber shading and detections (the + in Figures 3(a) and (b)). There is a cyclonic circulation around the low centre and precipitation occurs only where there is onshore westerly or northeasterly flow. The heat low remains stationary over the north-west of the continent on the $10^{t h}-11^{\text {th }}$ January 2010 but the region of precipitation (and the associated northeasterly flow) moves westward relative to the 

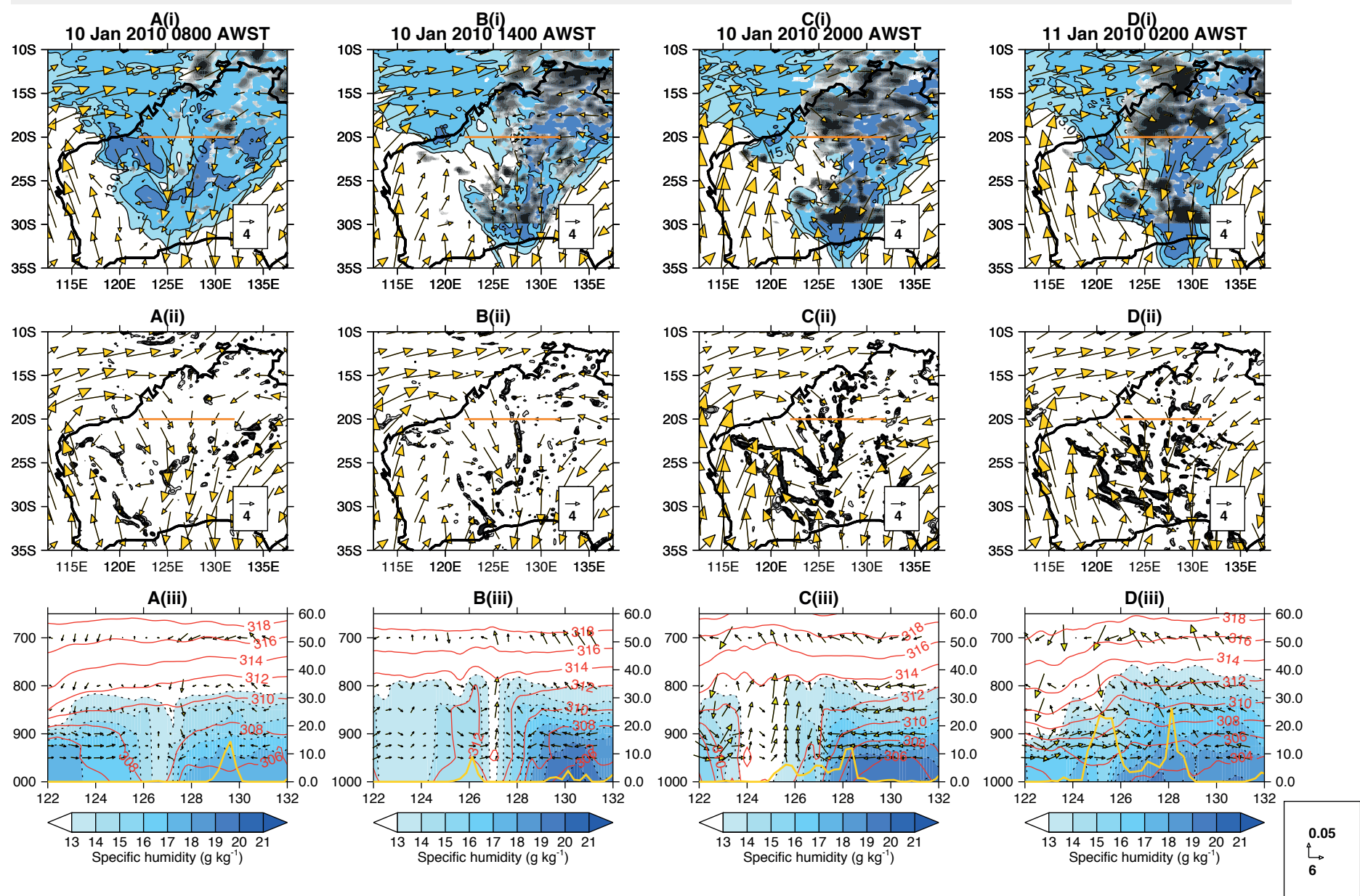

Figure 4. Case study analysis of 6-hourly circulation fields and specific humidity from the YOTC reanalysis and precipitation data are from CMORPH: top row-925 $\mathrm{hPa}$ flow (arrows, $\mathrm{m} \mathrm{s}^{-1}$ ) and specific humidity (blue, $\mathrm{g} \mathrm{kg}^{-1}$ ) with regions of precipitation $>0.25 \mathrm{~mm}^{-1} \mathrm{hr}^{-1}$ shaded grey-black; middle row-925 hPa flow (arrows, $\mathrm{m} \mathrm{s}^{-1}$ ) and regions with moisture flux convergence $>6.0 \times 10^{-7} \mathrm{~s}^{-1}$ shaded black; bottom row-vertical cross section along the orange line shown in the top two rows containing the combined horizontal and vertical flow (arrows, $\mathrm{m} \mathrm{s}^{-1}$ ), virtual potential temperature (orange contours, $\mathrm{K}$ ) and specific humidity (blue shading, $\mathrm{g} \mathrm{kg}^{-1}$ ) on pressure levels. Also shown in the bottom row is the rainfall $\pm 3 \mathrm{hr}$ of the analysis time (yellow line, scale on right hand y-axis, mm). Vertical columns (left to right) are representative of these features at 0800 AWST $10^{t h}$ January, 1400 AWST $10^{t h}$ January, 2000 AWST $10^{t h}$ January and 0200 AWST $11^{t h}$ January 2010. Circulation fields and specific humidity are plotted from the YOTC reanalysis and precipitation data are from CMORPH.

$8^{\text {th }}-9^{\text {th }}$ January (compare Figures 3(c) and (d) with (a) and (b)).

There is very little precipitation within the heat low centre itself, which suggests there is insufficient moisture to allow it (Figures 3(c) and (d)).

Overall, there is a clearly defined heat low structure on the $8^{\text {th }}$ $11^{\text {th }}$ January 2010. Furthermore, there is little or no precipitation within the heat low centre itself, which also suggests that the presence of a heat low alone is not sufficient to cause nocturnal rainfall. Given the different synoptic situation during $10^{t h}-12^{\text {th }}$ January (Figure 3), the 6-hourly evolution for $10^{t h}-11^{\text {th }}$ January is investigated in more detail, to better understand the specific mechanisms at work (Figure 4). The low-level specific humidity and flow (top row), moisture flux convergence (middle row) and vertical transects of humidity, temperature and winds (bottom row) are plotted in Figure 4.
There is a tongue of relatively moist air over the continent (blue shading, Figure 4A(i)), which is associated with easterly to northeasterly flow at low levels $(925 \mathrm{hPa})$. There are also some small regions of precipitation in the north-east of the plotted domain at 0800 AWST (grey shading, Figure 4A(i)). The heat low detections in Figure 3(c) correspond with the region of relatively low specific humidity (i.e. $<13 \mathrm{~g} \mathrm{~kg}^{-1}$ in Figure $4 \mathrm{~A}(\mathrm{i})$ ) and cyclonic circulation, westward of approximately $120^{\circ} \mathrm{E}$. There are narrow bands of strong moisture flux convergence (Figure 4A(ii), black shading) over western Australia and along $25^{\circ} \mathrm{S}$. A developing heat low is also visible (Figure $4 \mathrm{~A}$ (iii) near $126^{\circ} \mathrm{E}$, isothermal layer from the surface to approximately $900 \mathrm{hPa}$ ). Also notice the region of reduced specific humidity, which coincides with the developing heat low and is a signature of dry convection acting to reduce the low-level moisture (through vertical mixing). 
By 1400 AWST, surface solar heating has caused the lowlevel winds (925 hPa) to weaken (as described in Section 3.1) and turn cyclonically relative to 0800 AWST (Figures 4B(i) and B(ii)). Rainfall is visible in the relatively moist air (blue shading in Figure 4B(i)). A convergence zone has formed along the boundary between the relatively high and low specific humidity air mass $\left(127^{\circ} \mathrm{E}\right.$, Figure $\left.4 \mathrm{~B}(\mathrm{ii})\right)$. The heat low has also deepened between 0800 to 1400 AWST (compare Figures 4B(iii) and A(iii)), with the isothermal layer extending to approximately $775 \mathrm{hPa}$. Ascent, associated with the convergence zone in Figure 4B(ii), is also visible in Figure $4 \mathrm{~B}$ (iii) around $127^{\circ} \mathrm{E}$.

Rainfall increases and becomes more widespread around 2000 AWST relative to 1400 AWST (compare Figures 4C(i) and $\mathrm{B}(\mathrm{i})$, darker shading) despite insolation reducing during this time (sunset occurs between 1800-1900 AWST). The 925 hPa wind strengthens relative to 1400 AWST, which is indicative of a reduction in the low-level drag (discussed in Section 3.1). Air parcels tend to accelerate down the pressure gradient as the drag reduces. The nocturnal convergence however, is not solely focused within the centre of the heat low (around $117^{\circ} \mathrm{E}, 22^{\circ} \mathrm{S}$ in Figure 3(c)) and there are several convergence lines over the continent (Figure 4C(ii), black shading). The convergence and ascent are also visible in the horizontal cross section (Figure 4C(iii)) around $126^{\circ} \mathrm{E}$. Precipitation is visible in the ascending, higher specific humidity air to the east of $125^{\circ} \mathrm{E}$ but there is no precipitation between $123^{\circ} \mathrm{E}-125^{\circ} \mathrm{E}$ where the specific humidity is lower.

Around 0200 AWST, the precipitation lies within the (relatively) moist, northeasterly flow (Figure 4D(i)). The relatively higher humidity air is advected westward relative to 2000 AWST within the prevailing northwesterly to northeasterly flow (compare Figures $4 \mathrm{C}(\mathrm{i})$ and $\mathrm{D}(\mathrm{i})$ ). The flow also turns anticyclonically by 0200 AWST relative to 2000 AWST (i.e. geostrophic balance, see Section 3.1). The remaining convergence zones lie within the relatively moist air (compare Figures 4D(i) and D(ii)); however the convergence zones northward of $20^{\circ} \mathrm{S}$ are weaker at 0200 AWST relative to 2000 AWST. Along the transect, the easterly low-level flow rises up the isentropic surfaces around $124^{\circ} \mathrm{E}$, which is associated with the leading edge of the precipitation along the cross section (Figure 4D(iii)).
In this case, the nocturnal convergence around the heat low circulation does not occur over a broad area (as could be implied from Figures 2(c) and (d) where the strong convergence occurs over much of the continent); instead, the convergence is organised into disparate convergence zones or lines (Arnup and Reeder 2007; Deslandes et al. 1998). The nocturnal rearrangement of the low-level flow (around the heat low) can intensify local moisture gradients at the boundary between moist (tropical) and dry (continental) air masses. Such boundaries are termed "drylines" and are a common feature over northern Australia (Arnup and Reeder 2007). As the air masses do not mix across the dryline, they are also the focus of convergence and ascent (Arnup and Reeder 2009) and (it would seem) can play a key role in the development of nocturnal rainfall. Furthermore, there is evidence that other types of convergence zones (for example a seabreeze front-see Section S1.2.3 in the Supplementary Material) may strengthen as the flow rearranges overnight and can also become the focus for precipitation.

It is clear from Figure 5 (and those in the Supplementary Material) that the along-convergence line boundary may extend for thousands of kilometres but the cross-convergence line boundary is much narrower (10-100 km, see Arnup and Reeder 2009). Therefore, as in the case presented in Figure 5 (and those in the Supplementary Material) the actual convergence zones that form on any given day are likely to cover a much smaller area than that implied by the climatological analysis in Figure 2. Diagnosing any such convergence features and attributing rainfall to them is the focus of the next sub-section in order to address their general importance from a climatological perspective.

\subsection{Nocturnal convergence lines and precipitation}

The frequency of convergence lines $\left(\%\right.$ month $\left.^{-1}\right)$ at each grid point from ERA-Interim over north-west Australia in DJF are plotted in Figure 5. Within the domain of interest (box in Figure 5) convergence zones are detected $>20 \%$ of the time on individual grid points at 2000 and 0200 AWST (Figures 5(a) and (b)), consistent with the climatological mean presented in Figures 2(c) and (d).

The fraction of total precipitation associated with convergence lines over north-west Australia is plotted in Figures 5(c) and 


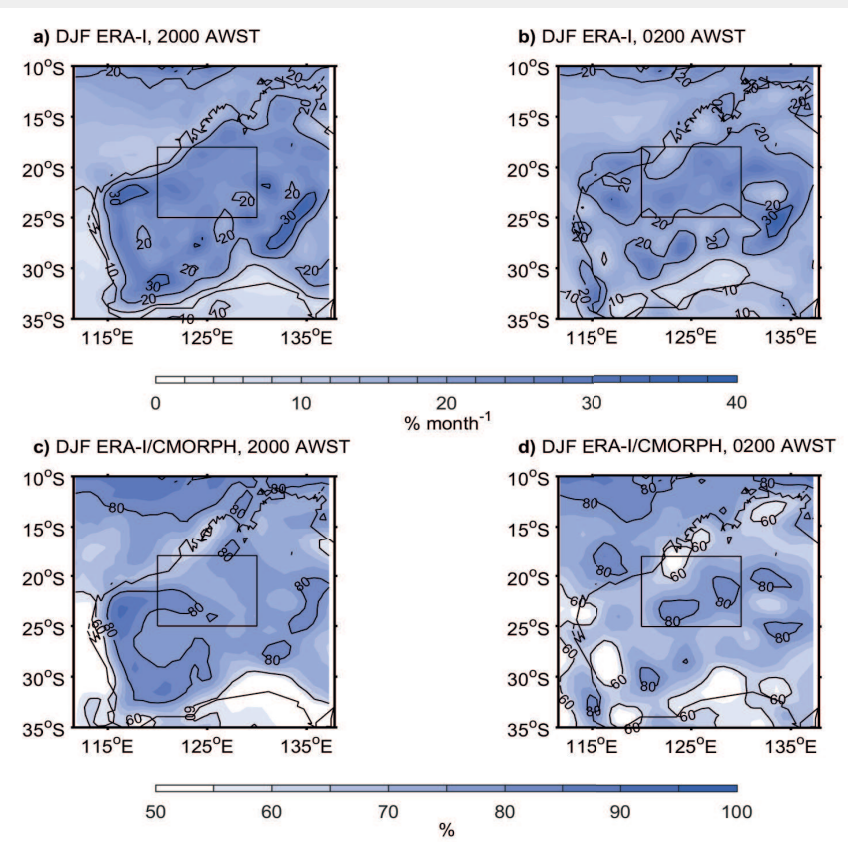

Figure 5. The frequency of detected convergence lines at each grid point taken for all DJFs (1979-2013) from ERA-Interim at (a) 2000 AWST and (b) 0200 AWST. The fraction of CMORPH (1998-2013) precipitation attributed to the identified convergence zones \pm 3 hours of (c) 2000 AWST and (d) 0200 AWST.

(d) (for $2000 \pm 3 \mathrm{hr}$ and $0200 \pm 3 \mathrm{hr}$ AWST, respectively). The algorithm used identifies precipitation first and then associates it with nearby convergence zones, therefore non-precipitating convergence lines are eliminated from the analysis. It is clear that most of the climatological rainfall $(>70 \%)$ at 2000 AWST is associated with a convergence line within the region of interest (Figure 5(c)) and the fraction increases (to >80\%) around 0200 AWST (Figure 5(d)). Ergo, when sufficient moisture is available, it is the narrow convergence lines that form around the heat low (and not a broad, continental-scale region of convergence as implied in Figures 2(c) and (d)) that deliver the majority of the rainfall overnight.

\subsection{Discussion}

Ackerley et al. (2014, 2015) and Berry et al. (2011) show that there is a tendency for more precipitation over north-west Australia overnight than during daylight hours (also see Figure 1(a)). Nevertheless, both Ackerley et al. (2014, 2015) and Berry et al. (2011) present composites (i.e. an average) of the circulation features that bring rainfall to north-west Australia, which smooths the features identified in Section 3.2. Instead of a broad area of nocturnal convergence within the heat low over north-west Australia (as can be seen in Figures 2(c) and (d)), distinct convergence lines develop and the resulting precipitation is organised around those zones. Furthermore, given composites may not be representative of the weather on any single day (i.e. individual events do not look exactly like the average—as seen in Figure 4), the assessment of the sub-daily processes at work is even more important.

One of the important ingredients for causing nocturnal rainfall is the presence of a heat low and, specifically, the diurnal reorganisation of the flow around it. A heat low is visible on $10^{\text {th }}$ January and had been present from the $8^{\text {th }}$ (Figure 3 ). Nevertheless, there is actually very little precipitation within the heat low itself (Figure 3(c), indicated by the $312 \mathrm{~K}$ isentrope shading), which is due to a lack of available moisture (see Figures 4A(i), B(i), C(i) and D(i)). Convergence zones that form within that relatively dry air are not associated with precipitation (see Figures 4C(i) and (ii)). Therefore, convergence alone is not sufficient to initiate precipitation, which is consistent with the findings of Berry et al. (2011).

Conversely, where there is sufficient moisture present, the down-pressure gradient acceleration of the flow around 2000 AWST strengthens the existing moisture gradient into a dryline (as described in Arnup and Reeder 2007). These drylines may then become the primary focus for convergence (ascent) and precipitation (compare Figures $4 \mathrm{~B}$ (iii) and $\mathrm{C}(\mathrm{iii})$ ). The precipitation forms on the relatively moist side of the dryline as the higher moisture air ascends above the relatively dry air. Therefore, it is the reorganization of the flow at the dryline that drives precipitation and the heat low itself is only responsible for creating the necessary conditions for that reorganisation to happen. Furthermore, precipitating convergence zones are responsible for causing $>70 \%$ of the precipitation that occurs overnight.

As the features identified above (convergence zones and heat lows) span hundred of kilometres, it may be possible for coarseresolution GCMs to represent such circulation features over northwest Australia (especially as GCMs have been shown to represent analogous mid-latitude features, i.e. fronts-see Catto et al. 2012). Furthermore, the GCMs used in CMIP5 also simulate a secondary increase in convergence and precipitation overnight in north-west Australia (Ackerley et al. 2015). If precipitation in the GCMs is associated with convergence across e.g. a dryline, and 
not widespread nocturnal convergence, then it can be argued that they are capturing the correct physical processes that cause nighttime rainfall. This is investigated for a selection of models in the following sections.

\section{MetUM: Par12k simulation}

\subsection{Mean diurnal circulation and nocturnal precipitation}

The fraction of precipitation that occurs overnight (2000 AWST0800 AWST) from Par12k (averaged over all 3 years of the simulation) is plotted in Figure 1(b). There are many areas where more than $35 \%$ of the precipitation occurs between sunset and sunrise (dark shading in Figure 1(c)), which is a smaller proportion than for CMORPH (compare with Figures 1(a) and (b)). The small nocturnal rainfall contribution (to the daily total) is due to most of the precipitation falling between 11001400 AWST, which is associated with the early triggering of the parametrized convection (and is a common problem across models, see Yang and Slingo 2001; Dai 2006; Dirmeyer et al. 2012; Ackerley et al. 2015; Birch et al. 2015). Nevertheless, when the mean diurnal cycle is considered (Figure 1(d), purple line), there is a clear secondary peak in precipitation between 20002300 AWST that cannot be associated with a destabilization of the boundary layer from solar heating. This secondary peak is associated with the triggering of the "mid-level" (i.e. above the nocturnal boundary layer) convection scheme in the MetUM (see Walters et al. 2011, 2014). Therefore, given that the problems associated with the daytime convection are discussed elsewhere (e.g. Ackerley et al. 2014, 2015; Brown et al. 2010; Stratton and Stirling 2012), it is worth focussing on the cause of the nocturnal precipitation peak here to see whether it is caused by the same processes described in Section 3.

The first step is to identify whether the mean diurnal circulation in Par12k is comparable with the reanalysis data. The mean diurnal, $925 \mathrm{hPa}$ circulation (averaged over the three simulated years) at 0800, 1400, 2000 and 0200 AWST are plotted in Figures 2(e)-(h), respectively. There is a cyclonic circulation centre over north-west Australia with predominantly easterly flow over the rest of the continent at 0800 AWST, which then weakens and turns cyclonically by 1400 AWST (Figures 2(e) and (f)) and is

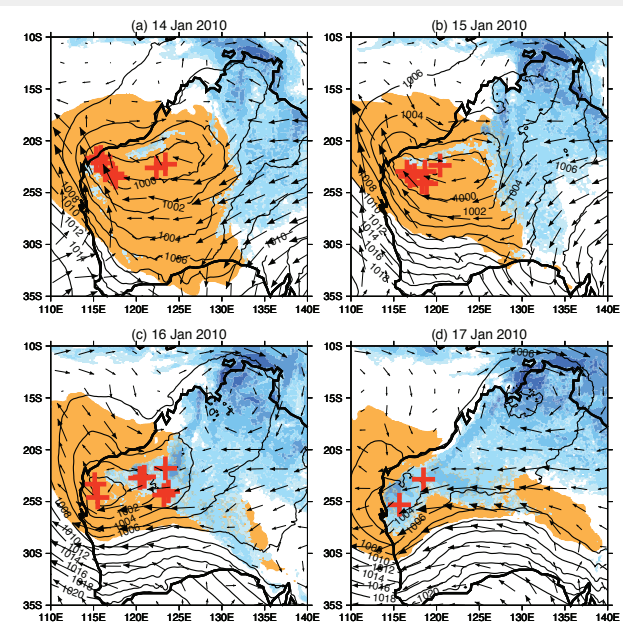

Figure 6. Par12k case study mean sea level pressure, hPa (solid lines), $850 \mathrm{hPa}$ winds, $\mathrm{m} \mathrm{s}^{-1}$ (arrows), daily rainfall $\geq 2 \mathrm{~mm}$ (blue shading), $850 \mathrm{hPa}$ potential temperature $\geq 312 \mathrm{~K}$ (amber shading) and identified heat low centres ("+" in the figure) from the detection algorithm described in Section 2.3 (all 6-hourly detections are included in each daily plot) for (a) $14^{t h}$ January 2010 , (b) $15^{t h}$ January 2010 , (c) $16^{\text {th }}$ January 2010 and (d) $17^{t h}$ January 2010.

also seen for ERA-Interim (Figures 2(a) and (b)). Furthermore, the air accelerates towards the north-west of the continent at 2000 AWST (as the nocturnal stable layer forms) causing an increase in convergence over the land (Figure 2(g)). By 0200 AWST, the flow has turned anticyclonically relative to 2000 AWST and circulates around approximately $23^{\circ} \mathrm{S}$ and $124^{\circ} \mathrm{E}$ (Figure 2(h)). There is also a broad area of convergence visible at 2000 and 0200 AWST, which compares well with ERA-Interim (Figure 2(d)). The coincidence of the secondary nocturnal precipitation peak (between 2000-2300 AWST) and the increased convergence would suggest the two are related. Therefore, it is worth investigating a case study to identify whether the processes described in Section 3.2 (i.e. for the real world) also occur in the Par12k simulation.

\subsection{Case Study}

As with the reanalysis-CMORPH case study (Section 3.2), a period of increased nocturnal rainfall is identified from the Par12k simulation between $14^{\text {th }}-17^{\text {th }}$ January 2010 (reminder: Par12k dates do not correspond to the real-world date and the actual weather in January 2010, see Section 2.2). Again, for brevity, only one day $\left(16^{\text {th }}-17^{\text {th }}\right)$ is considered despite there being several other case studies that could have been used (not shown); however, the two days that follow $\left(17^{t h}-19^{\text {th }}\right.$ January) are provided in the supplementary material (S2.1 and S2.2) for further supporting evidence of the atmospheric processes at work. 

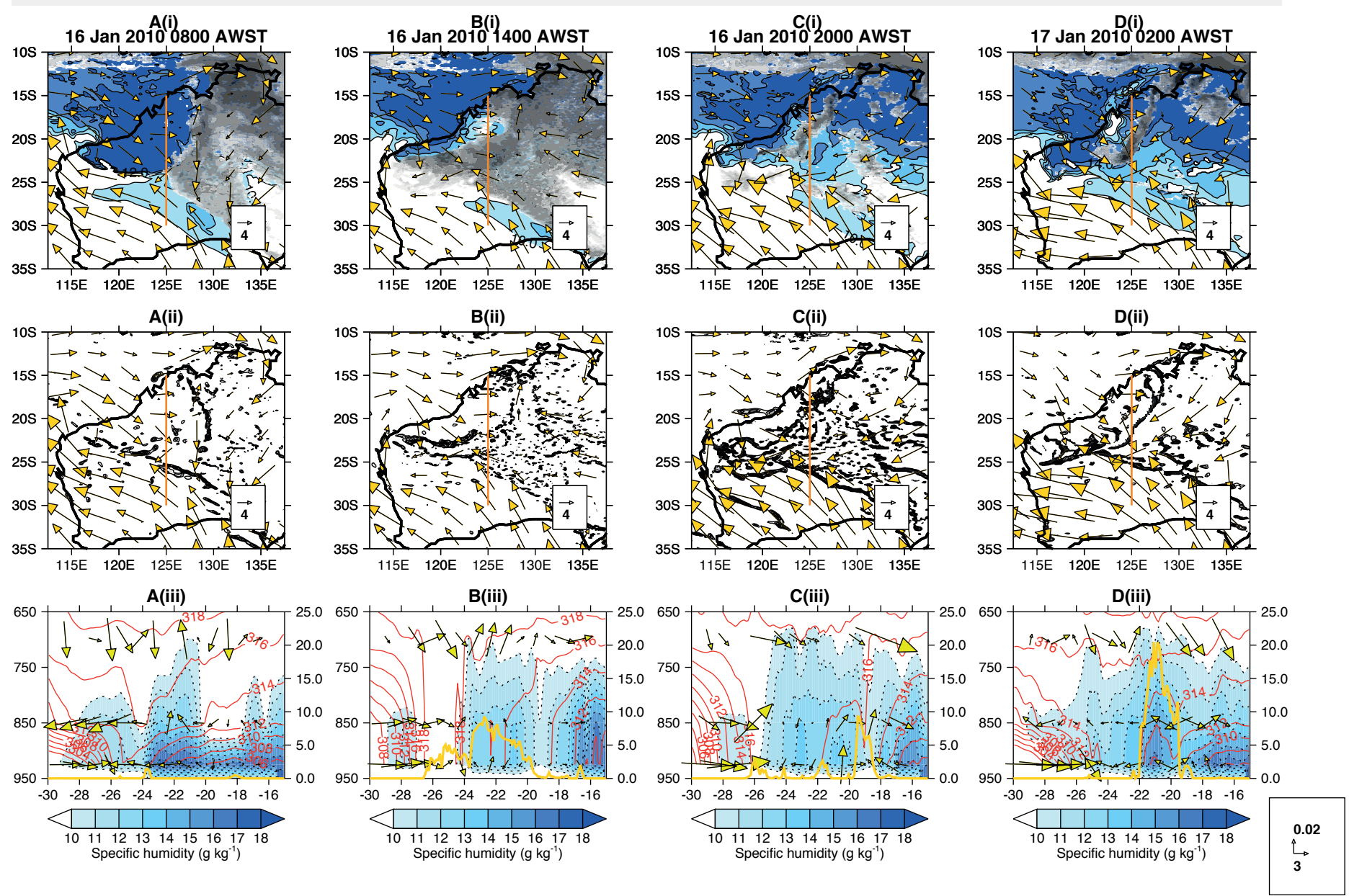

Figure 7. Case study analysis of 6-hourly data from the Par12k simulation: top row- $925 \mathrm{hPa}$ flow (arrows, $\mathrm{m} \mathrm{s}^{-1}$ ) and specific humidity (blue, $\mathrm{g} \mathrm{kg}^{-1}$ ) with regions of precipitation $>0.25 \mathrm{~mm}_{6 \mathrm{hr}^{-1}}$ shaded grey-black; middle row- $925 \mathrm{hPa}$ flow (arrows, $\mathrm{m} \mathrm{s}^{-1}$ ) and regions with moisture flux convergence $>6.0 \mathrm{x} 10-7 \mathrm{~s}-1$ shaded black; bottom row-vertical cross section along the orange line shown in the top two rows containing the combined horizontal and vertical flow (arrows, $\mathrm{m} \mathrm{s}^{-1}$ ), virtual potential temperature (orange contours, $\mathrm{K}$ ) and specific humidity (blue shading, $\mathrm{g} \mathrm{kg}^{-1}$ ) on pressure levels. Also shown in the bottom row is the rainfall $\pm 3 \mathrm{hr}$ of the analysis time (purple line, scale on right hand y-axis, mm). Vertical columns (left to right) are representative of these features at 0800 AWST $16^{t h}$ January, $^{\text {th }} 1400$ AWST $16^{t h}$ January, 2000 AWST $16^{\text {th }}$ January and 0200 AWST $17^{\text {th }}$ January 2010.

The synoptic situation for $14^{t h}-17^{t h}$ January 2010 from the Par12k simulation is presented in Figure 6 (using the same convention for the variables as in Figure 4). There is a heat low and associated cyclonic circulation between $115^{\circ} \mathrm{E}-125^{\circ} \mathrm{E}$ and approximately $22.5^{\circ} \mathrm{S}$ (Figure 6(a)) with precipitation primarily located within the northeasterly flow to the east of the low. The heat low centre remains in the north-west corner of the continent on $15^{\text {th }}-16^{\text {th }}$ January (Figures 6(b) and (c), respectively) but the region of precipitation, embedded within the easterly and northerly $850 \mathrm{hPa}$ flow, moves westwards. The heat low is still clearly visible in the north-west corner of the continent on $17^{\text {th }}$ January and the precipitation extends across the whole land mass northward of $20^{\circ} \mathrm{S}$ (within the easterly flow, Figure 6(d)).

There is a clearly defined heat low for the $14^{t h}-17^{t h}$ January with precipitation primarily to the east of the low's centre. The majority of the precipitation is embedded within the northerly/easterly flow and not the continental southeasterly flow.
Nevertheless, there is precipitation within the heat low itself, which is associated with onshore (northerly) flow across the northwest Australian coastline.

The sub-daily $925 \mathrm{hPa}$ circulation, precipitation, humidity and circulation features are plotted in Figure 7 for Par12k in the same way described in Section 3.3 (Figure 4). A broad region of high specific humidity air $\left(>10 \mathrm{~g} \mathrm{~kg}^{-1}\right)$ lies over the domain in northwesterly-to-northeasterly $925 \mathrm{hPa}$ flow (Figure 7A(i)) with lower humidity air in southerly-southeasterly flow. Precipitation is visible eastward of $125^{\circ} \mathrm{E}$ at 0800 AWST, which is characteristic of parametrized convection being triggered too early (Ackerley et al. 2015; Birch et al. 2015; Brown et al. 2010; Dai 2006; Stratton and Stirling 2012; Yang and Slingo 2001). There are two main convergence zones at 0800 AWST_-one along the boundary of the northwesterly and southeasterly $925 \mathrm{hPa}$ flow and the other between the northeasterly and northwesterly flow, along $129^{\circ} \mathrm{E}$ (Figure $7 \mathrm{~A}(\mathrm{ii})$ ). There is a tongue of relatively high 
specific humidity air over the continent (at $925 \mathrm{hPa}$ ) that extends to approximately $24^{\circ} \mathrm{S}$ (Figure $7 \mathrm{~A}(\mathrm{iii})$ ).

Around 1400 AWST, precipitation occurs throughout the region of higher specific humidity air (primarily within the $11 \mathrm{~g} \mathrm{~kg}^{-1}$ isohume) and the $925 \mathrm{hPa}$ flow weakens relative to 0800 AWST (compare Figures 7A(i) and B(i)). There are many small regions of convergence within the precipitating region (Figure $7 \mathrm{~B}(\mathrm{ii})$ ), which are consistent with the ERA-Interim case (see Section 3.3, Figure $4 \mathrm{~B}(\mathrm{ii})$ ). Along $22^{\circ} \mathrm{S}$ (approximately), there is a convergence zone between the onshore northwesterly and the continental southeasterly flows. The highest rainfall ( \pm 3 hours of 1400 AWST) is visible within a region of relatively high specific humidity (between $20^{\circ} \mathrm{S}-24^{\circ} \mathrm{S}$ ), bounded by two regions of lower specific humidity air (at $19^{\circ} \mathrm{S}$ and $26^{\circ} \mathrm{S}$ ) where the precipitation is also lower (see Figure 7B(iii)).

At 2000 AWST, the $925 \mathrm{hPa}$ flow strengthens (reduced low-level drag as the nocturnal boundary layer forms) and the precipitation organises into two lines-one at the northern extent of the southeasterly flow and the other parallel to the northern coastline (Figure 7C(i)). Both precipitation lines are associated with high values of moisture flux convergence (compare Figures 7C(i) and C(ii)). The precipitation occurs at the northern and southern boundaries of the relatively moist region at approximately $19^{\circ} \mathrm{S}$ and $25^{\circ} \mathrm{S}$ (see Figures 7C(iii) and B(iii)).

By 0200 AWST, the flow strengthens further and turns anticyclonically relative to 2000 AWST (compare Figure 7D(i) with $7 \mathrm{C}(\mathrm{i}))$. The northernmost line of precipitation moves inland and strengthens but the southern one has diminished (Figure 7D(i)). Both convergence zones (highlighted in Figure 7C(ii)) are visible at 0200 AWST (Figure $7 \mathrm{D}$ (ii)), but precipitation is restricted to the more northern zone where the northeasterly and northwesterly flows converge. Furthermore, specific humidity values are higher around $20^{\circ} \mathrm{S}-22^{\circ} \mathrm{S}$ (within the convergence of the northeasterly and northwesterly flow) than around $24^{\circ} \mathrm{S}-26^{\circ} \mathrm{S}$ (at the convergence of the southeasterly and northerly flow, Figure 7D(iii)).

In this case there appear to be two different convergence lines that are responsible for causing the nocturnal precipitation. The southern convergence zone $\left(\sim 25^{\circ} \mathrm{S}\right.$, Figures $\left.7 \mathrm{C}(\mathrm{i})-(\mathrm{iii})\right)$ is similar to the dryline case described in Section 3.2. The northern

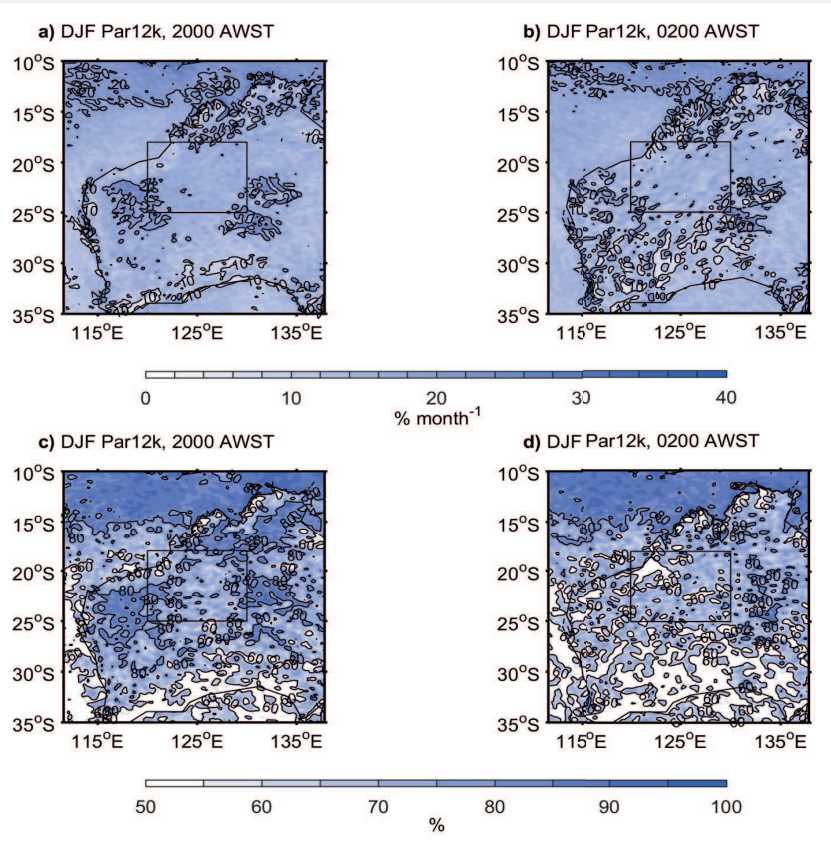

Figure 8. The frequency of detected convergence lines at each grid point taken for all DJFs (3 years) from Par12k at (a) 2000 AWST and (b) 0200 AWST. The fraction of Par12k DJF precipitation attributed to the identified convergence lines \pm 3 hours of (c) 2000 AWST and (d) 0200 AWST, taken over the same years.

convergence line however (parallel to the coast near $20^{\circ} \mathrm{S}$, Figures 7C(i)-(iii)), resembles a sea breeze front that has accelerated onshore from the coast following the nocturnal re-arrangement of the flow. Nocturnal convergence and precipitation associated with an onshore flow is also visible for the YOTC-CMORPH analysis (supplementary material Section S1.2 and Figure S1.2), which suggest that sea breeze fronts may also be important for the development of nocturnal precipitation in both Par12k and the real world. Precipitation associated with both drylines and sea breeze fronts is identified by the convergence line detection algorithm described in Section 2.4 as the calculations only consider convergence and not the thermodynamic properties of the atmosphere. Given that similar atmospheric processes in Par12k (relative to YOTC-CMORPH) appear to be responsible for nocturnal precipitation, the climatological (3-year) proportion of nocturnal rainfall associated with convergence zones is presented in the next section.

\subsection{Nocturnal precipitation and convergence}

The frequency of convergence zones $\left(\%\right.$ month $\left.^{-1}\right)$ that occur in DJF in the Par12k simulation are plotted for 2000 AWST and 0200 AWST in Figures 8(a) and (b), respectively. The areas with the highest number of detected convergence zones at 2000 and 0200 AWST correspond well with the region of higher nocturnal 
convergence in the climatological mean (compare Figures 8(a) and (b) with Figures 2(g) and (h)), as is also the case for ERAInterim (see Section 3.2). There are fewer convergence zone detections in Par12k ( 18\%-22\%, Figures $8(\mathrm{a})$ and (b)) than for ERA-Interim ( $\sim 25 \%$, Figures 5(a) and (b)); however, this is due to the smaller grid spacing in the Par12k simulations $(\sim 12 \mathrm{~km})$ than ERA-Interim $(\sim 80 \mathrm{~km})$ i.e. more grid points result in a reduced likelihood of a convergence line forming on a given point and time (highlighted and discussed further in Sections 5 and 6).

The fraction of precipitation associated with the convergence zones at 2000 and 0200 AWST $( \pm 3 \mathrm{hr})$ in Par12k are plotted in Figures 6(c) and (d), respectively. At 2000 AWST, precipitation is associated with a convergence line $>70 \%$ of the time (Figure $8(\mathrm{c})$ ) and $>60 \%$ of the time at 0200 AWST (Figure $8(d)$ ), which is comparable with the ERA-Interim analysis (Figures 5(c) and (d)). It is also clear that nocturnal precipitation in the Par12k simulation is primarily driven by the convergence zones forming overnight, provided there is sufficient moisture.

\subsection{Discussion}

The climatological location of nocturnal precipitation and convergence coincide in Par12k simulation (Figures 1(b) and, 2(g) and (h)). On the other hand, only some convergence zones are associated with precipitation overnight (see Figure 7) as is also seen in the observations (Figure 4). Precipitation only occurs at night where there is sufficient moisture present (i.e. relatively dry convergence zones do not precipitate). It seems that the presence of a heat low is also necessary to set up the conditions for nocturnal precipitation in Par12k (as also seen in the reanalysis data) but, as in the observations, there is little precipitation within the heat low itself (see Figure 6). Precipitation is also seen to occur at the boundary between moist and dry air masses around the heat low as the flow reorganises (e.g. where drylines develop; Figures 7C(i)-(iii)). Furthermore, precipitation also forms along the leading edge of a region of onshore flow (i.e. a sea breeze front). Finally, precipitating convergence zones are responsible for $\gtrsim 70 \%$ of the rainfall that occurs overnight. Therefore, despite the error in the daytime convection (a consequence of the triggering mechanism in the convection parametrization) the nocturnal precipitation seems to form under the correct synoptic conditions in the Par12k simulation.

Having identified that the processes are represented well in a high-resolution GCM ( $12 \mathrm{~km}$ grid spacing), the next section focuses on whether a low-resolution GCM simulation $(\sim 150 \mathrm{~km}$ grid spacing) can also represent the same processes.

\section{ACCESS1.0 N96}

\subsection{Nocturnal precipitation and mean diurnal cycle}

The fraction of precipitation that occurs between 2000 AWST and 0800 AWST in ACCESS1.0 is plotted in Fig. 1(c). Between 35\% and $50 \%$ of the simulated precipitation occurs when surface solar heating does not destabilise the boundary layer (i.e. overnight), which is lower than the CMORPH-derived estimate (Figure 1(a)). On the other hand, when the mean diurnal cycle within the box plotted in Figure 1(c) is considered, there are two clear peaks in precipitation-one around 1100-1400 AWST and the other from 1700-2000 AWST. Furthermore, precipitation remains $>0.1 \mathrm{~mm}$ $3 \mathrm{hr}^{-1}$ after 2000 AWST, which may therefore be caused by the same processes described in Sections 3 and 4.

As with ERA-Interim and Par12k, the mean diurnal cycle of the $925 \mathrm{hPa}$ circulation is plotted in Figure 2(i)-(l) for ACCESS1.0. The mean diurnal cycle of the $925 \mathrm{hPa}$ flow in ACCESS1.0 is very similar to both ERA-Interim and Par12k, with a cyclonic circulation over north-west Australia at 0800 AWST (Figure 2(i)), which weakens and turns cyclonically by 1400 AWST (Figure 2(j)). Again, it is the low-level turbulence from daytime surface heating that acts to weaken the mean flow. Once the nocturnal boundary layer forms at 2000 AWST (Figure 2(k)), the flow accelerates towards the climatological heat low centre and causes an increase in convergence. The flow then turns anticyclonically by 0200 AWST relative to 2000 AWST and the convergence weakens as the flow tends towards geostrophic balance (Figure 2(1)). This sequence of events is ubiquitous in ACCESS1.0, ERAInterim and Par12k. In the next section therefore, a specific case study is presented in order to ascertain whether the same processes identified in Sections 3 and 4 also occur in ACCESS1.0. 


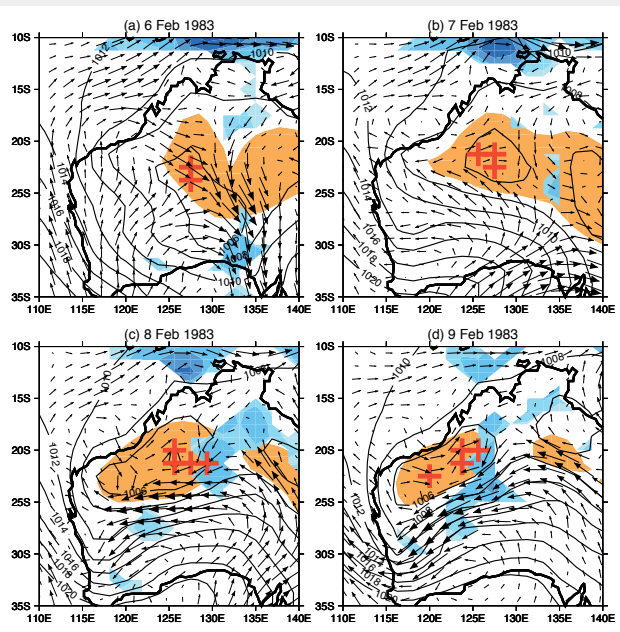

Figure 9. ACCESS1.0 case study analysis of mean sea level pressure, hPa (solid lines), $850 \mathrm{hPa}$ winds, $\mathrm{m} \mathrm{s}^{-1}$ (arrows), daily rainfall $\geq 2 \mathrm{~mm}$ (blue shading), 850 $\mathrm{hPa}$ potential temperature $\geq 312 \mathrm{~K}$ (amber shading) and identified heat low centres ("+" in the figure) from the detection algorithm described in Section 2.3 (all 6hourly detections are included in each daily plot) for (a) $6^{\text {th }}$ February 1983, (b) $7^{t h}$ February 1983, (c) $8^{t h}$ February 1983 and (d) $9^{t h}$ February 1983.

\subsection{Case study}

A selection of days with relatively high proportions of nocturnal precipitation are selected from the ACCESS1.0 simulation, as was also the case for CMORPH and Par12k (see Sections 3 and 4). Only one day is presented in the main text to highlight the salient processes responsible for the nocturnal precipitation $\left(8^{\text {th }}-9^{\text {th }}\right.$ February 1983); however, a similar analysis of the two following days $\left(9^{t h}-11^{t h}\right.$ February 1983) are presented in the supplementary material (Sections S3.1 and S3.2). Other nocturnal rainfall cases have also been identified throughout the model simulation, but are not shown (again for brevity). Furthermore, the ACCESS1.0 dates do not correspond to the real-world date and the actual weather in February 1983 (see Section 2.2)

There is a heat low centre near to $130^{\circ} \mathrm{E}$ and $24^{\circ} \mathrm{S}$ (Figure 9(a)) on $6^{\text {th }}$ February. A cyclonic circulation at $850 \mathrm{hPa}$ is also visible on $7^{\text {th }}$ February with onshore northeasterly flow on to the continent (north-east quadrant of Figure 9(b)). The northeasterly flow extends to approximately $130^{\circ} \mathrm{E}$ and $22^{\circ} \mathrm{S}$ and is associated with precipitation. The heat low (indicated by the "+") moves towards the coastline and extends westward on $8^{t h}-9^{\text {th }}$ February (Figures 9(c) and (d)). The precipitation also extends towards the south-west but remains within the northeasterly flow (that initially developed on $7^{\text {th }}$ ). Overall, there is a clearly defined heat low and precipitation on $8^{t h}$ and $9^{\text {th }}$ February and again, there is little precipitation within the identified heat low itself. As in Sections 3.2 and 4.2 , the sub-daily circulation is now considered on one day
( $8^{\text {th }}$ February) in order to identify how the nocturnal convergence initiates rainfall in ACCESS1.0.

The sub-daily (6-hourly) specific humidity, $925 \mathrm{hPa}$ circulation, precipitation and temperature fields are plotted in Figure 10 for ACCESS1.0 in the same way described in Section 3.2 (Figure 4). A region of relatively moist air (specific humidity $>8 \mathrm{~g}$ $\mathrm{kg}^{-1}$ ) can be seen over the continent in Figure 10A(i) along with predominantly easterly flow over much of north-west Australia southward of $22^{\circ} \mathrm{S}$ (and westerly flow northward of that). There is a convergence zone between $20^{\circ} \mathrm{S}$ to $25^{\circ} \mathrm{S}$ (at the boundary between the easterly and westerly flow at $925 \mathrm{hPa}$ ), which is not associated with precipitation westward of $130^{\circ} \mathrm{E}$ (Figure 10A(ii)). There is a north-south moisture gradient along $130^{\circ} \mathrm{E}$ (Figure $10 \mathrm{~A}(\mathrm{iii}))$ with higher specific humidity in the north than the south. The initial development of a heat low is also visible within Figure 10A(iii) where the isentropes intersect with the land surface around $21^{\circ} \mathrm{S}$.

By 1400 AWST, the low-level flow (925 hPa) weakens over the land (surface heating and an increase in the low-level drag) relative to 0800 AWST (compare Figures 10B(i) and A(i)). A reduction in low-level specific humidity from 0800 AWST to 1400 AWST is also visible, which is associated with (dry) convection in the boundary layer. Areas of precipitation (grey shading, Figure $10 \mathrm{~B}(\mathrm{i}))$ are visible in the north-east corner of the plotted region but there is little precipitation westward of approximately $130^{\circ} \mathrm{E}$. The moisture flux convergence zones are weaker at 1400 AWST relative to 0800 AWST (compare Figures 10B(ii) and A(ii)) over most of the land surface, except where there is precipitation. There is a well-developed heat low (Figure 10B(iii)) centred around $20^{\circ} \mathrm{S}$ where the $310 \mathrm{~K}$ virtual potential temperature contour intersects with the surface. Furthermore, the precipitation in the plotted transect coincides with both a region of higher specific humidity and ascent between $20^{\circ} \mathrm{S}-24^{\circ} \mathrm{S}$.

The formation of the nocturnal boundary layer causes the low-level flow to accelerate across the tongue of higher specific humidity air at 2000 AWST (Figure 10C(i)). A region of strong moisture flux convergence forms where the flow converges (dark shading, Figure 10C(ii)) with the northern portion of the convergence zone coinciding with the precipitation $( \pm 3$ hours of 2000 AWST). The highest precipitation is visible around 


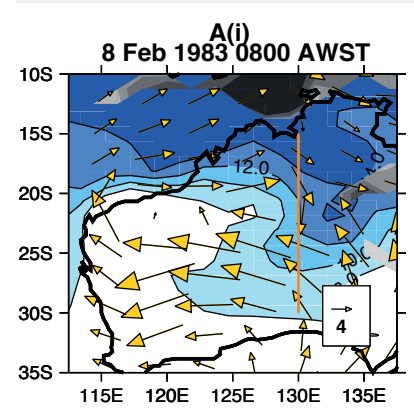

A(ii)
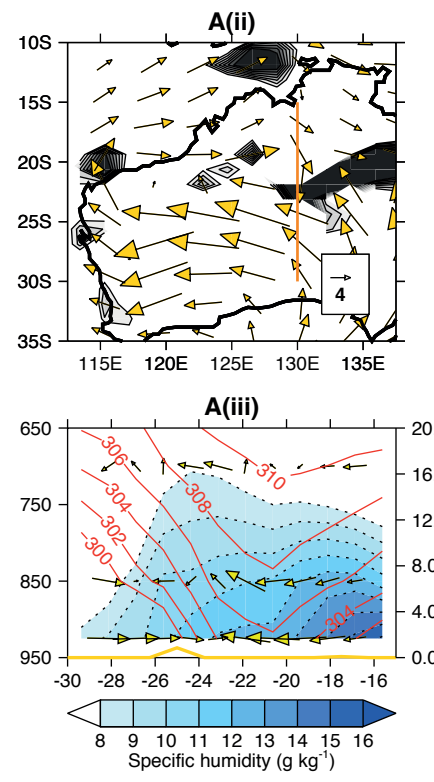

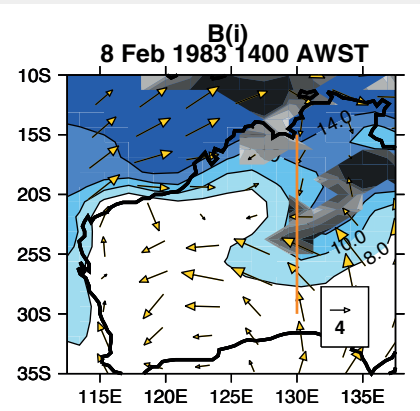

B(ii)

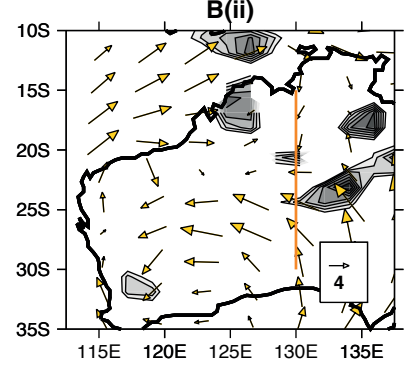

B(iii)

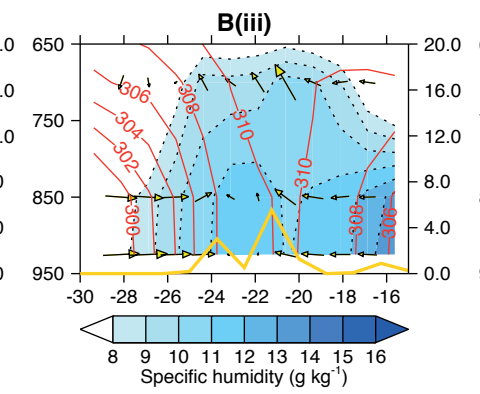

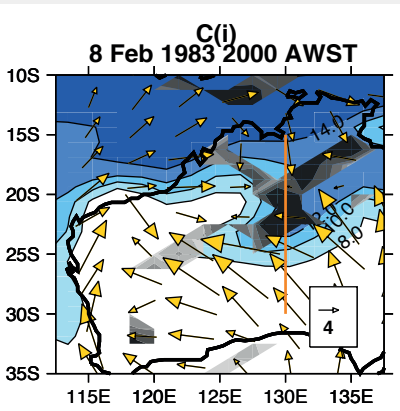

C(ii)
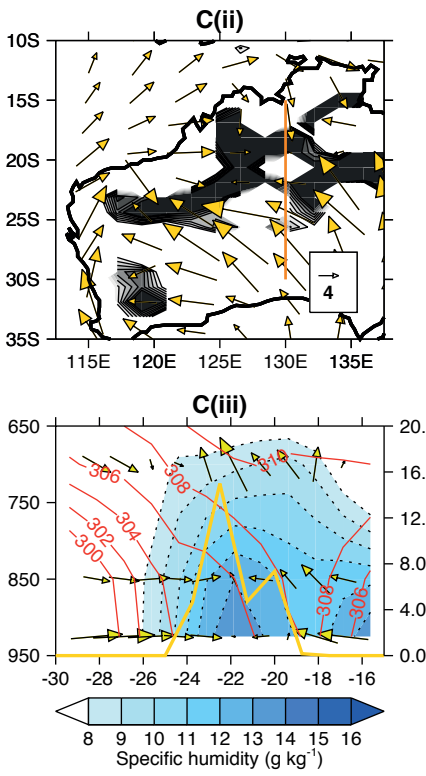

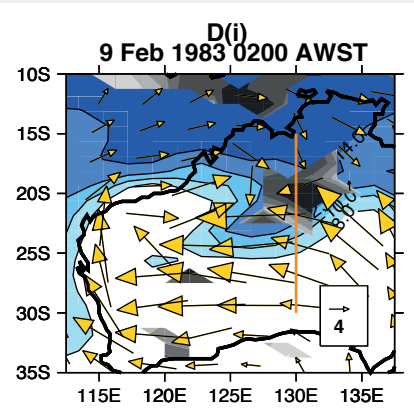

D(ii)

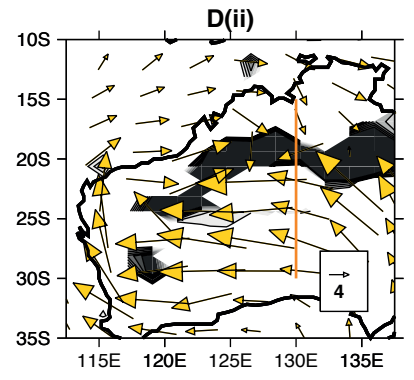

D(iii)

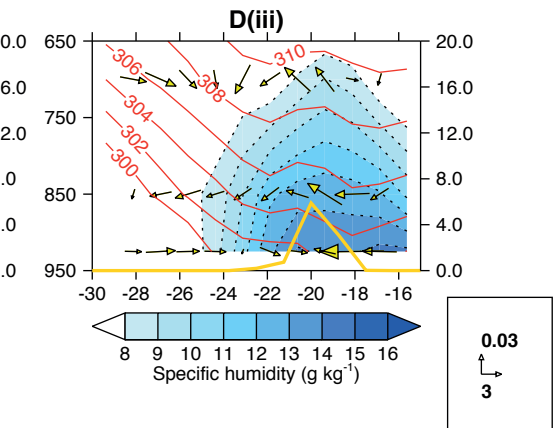

Figure 10. Case study analysis of 6-hourly data from ACCESS1.0: top row-925 hPa flow (arrows, $\mathrm{m} \mathrm{s}^{-1}$ ) and specific humidity (blue, $\mathrm{g} \mathrm{kg}^{-1}$ ) with regions of

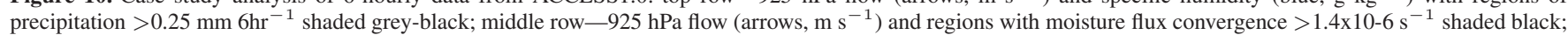
bottom row-vertical cross section along the orange line shown in the top two rows containing the combined horizontal and vertical flow (arrows, $\mathrm{m} \mathrm{s}^{-1}$ ), virtual potential temperature (orange contours, $\mathrm{K}$ ) and specific humidity (blue shading, $\mathrm{g} \mathrm{kg}^{-1}$ ) on pressure levels. Also shown in the bottom row is the rainfall $\pm 3 \mathrm{hr}$ of the analysis time (purple line, scale on right hand y-axis, mm). Vertical columns (left to right) are representative of these features at 0800 AWST $8^{t h}$ February, 1400 AWST $8^{t h}$ February, 2000 AWST $8^{t h}$ February and 0200 AWST $9^{\text {th }}$ February 1983.

$22^{\circ} \mathrm{S}$ where there is also strong convergence and ascent (Figure $10 \mathrm{C}(\mathrm{iii}))$. In this case, the formation of the convergence zone appears to play a key role in the development of the precipitation after sunset in ACCESS1.0. Conversely, there is little precipitation in the relatively dry air to the west of $125^{\circ} \mathrm{E}$ despite the strong convergence there.

The flow strengthens further by 0200 AWST relative to 2000 AWST (compare Figures $10 \mathrm{D}(\mathrm{i})$ and $\mathrm{C}(\mathrm{i})$ ) around $22^{\circ} \mathrm{S}$ and $130^{\circ} \mathrm{E}$. The precipitation coincides with a convergence zone; however, precipitation does not occur everywhere along the convergence zone (Figure 10D(ii)). The precipitation happens within the tongue of moist air where there is ascent along the isentropic surfaces (Figure 10D(iii)). Both the vertical motion and precipitation are considerably weaker at 0200 AWST than at 2000 AWST.

A similar set of processes (despite the geographical location differing slightly) to those seen in the observations (see Section
3) occur in this ACCESS1.0 case-i.e. weakening of the daytime circulation from dry convection and moisture convergence maintaining or initiating rain at night. The convergence zones are spatially larger in ACCESS1.0 than in ERA-Interim or the Par12k model, which is a reflection of the lower resolution of ACCESS1.0 ( $\sim 150 \mathrm{~km}$ grid spacing).

\subsection{Nocturnal convergence and associated precipitation}

The frequencies of occurrence of convergence zones $\left(\%\right.$ month $\left.^{-1}\right)$ in DJF simulated by ACCESS1.0 are plotted in Figures 11(a) and (b). Within the plotted box, convergence zones are typically detected $>30 \%$ of the time at both 2000 AWST and 0200 AWST and correspond with the high climatological mean convergence plotted in Figures 2(k) and (1), respectively. The frequencies are higher in ACCESS1.0 than in ERA-Interim; however, this is likely to be due to the lower resolution of ACCESS1.0 than ERAInterim (i.e. fewer grid points over which convergence zones can 


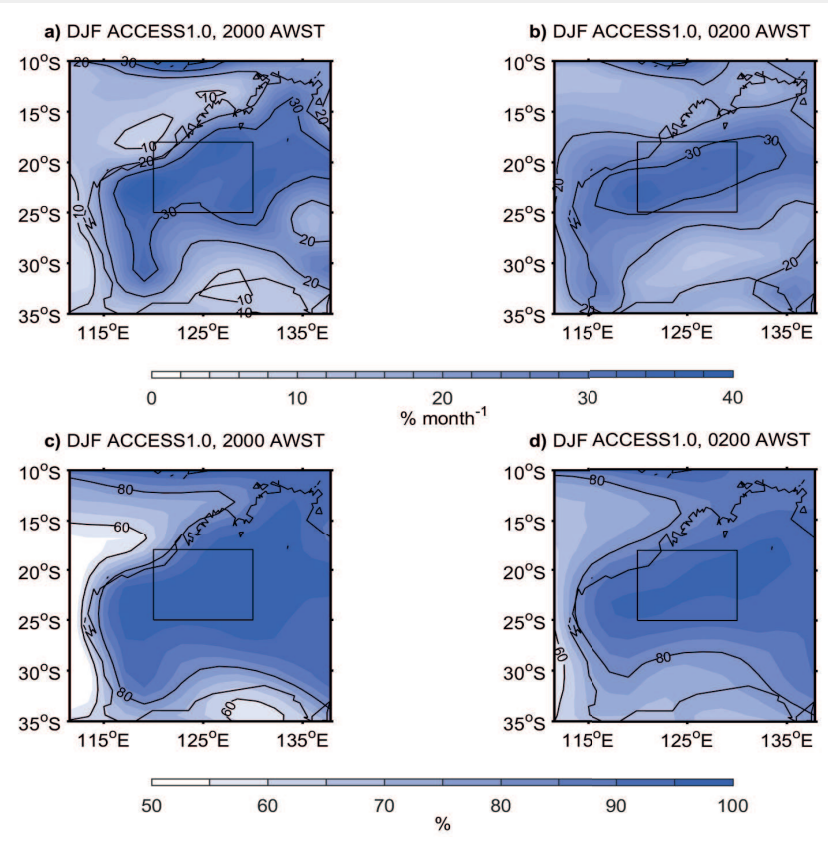

Figure 11. The frequency of detected convergence lines at each grid point taken for all DJFs (1979-2001) from ACCESS1.0 at (a) 2000 AWST and (b) 0200 AWST. The fraction of ACCESS1.0 DJF precipitation attributed to the identified convergence zones \pm 3 hours of (c) 2000 AWST and (d) 0200 AWST, taken over the same years.

develop at any time-also see Section 6). Despite the difference in frequency, the highest proportion of convergence zones occur parallel to the northern and western coasts at 2000 AWST, and are then confined to a relatively narrow band orientated south-west to north-east between $115^{\circ} \mathrm{E}-135^{\circ} \mathrm{E}$ (also seen for ERA-Interimcompare Figures 11(a) and (b), and 5(a) and (b)).

The fractions of precipitation associated with the identified convergence zones (\%) are plotted in Figures 11(c) and (d). At both 2000 AWST and 0200 AWST $>85 \%$ of the precipitation (within \pm 3 hours of those times) can be attributed to convergence zones. Again, this high proportion may be associated with the search radius of \pm 1 grid point, which is larger in the ACCESS1.0 simulations $(\sim 150 \mathrm{~km})$ than ERA-Interim/CMORPH $(\sim 80 \mathrm{~km})$. It is clear from Figures 11(c) and (d) however, that the formation of convergence zones is key to causing precipitation overnight (as in Par12k).

\subsection{Discussion}

As can clearly be seen in Figures 1(c) and, 2(k) and (1) the climatological nocturnal precipitation corresponds well with the strong convergence, which is also seen in ERAInterim and CMORPH (Figures 1(a) and, 2(c) and (d)). More importantly, when looking at the individual cases (Section 5.2 and, Supplementary Material S3.1 and S3.2), precipitation only occurs at night where there is sufficient moisture present i.e. relatively dry convergence zones do not precipitate, which is also seen in Par12k (Section 4) and the observations (Section 3). Furthermore, the presence of a heat low is also necessary to set up the conditions for nocturnal precipitation but, as in the observations and Par12k, there is little precipitation within the heat low itself (see Figure 10). In the ACCESS1.0 case (Figure 10), precipitation occurs within the relatively moist tongue of air adjacent to the heat low. The lifting of the relatively moist air from the north is caused by the convergence with the drier air to the south (i.e. a dryline, Figure 10C(i)-(iii)). The convergence zone and across-dryline moisture gradients are spread over $\sim 300 \mathrm{~km}$ (due to the coarse grid spacing), but the precipitation occurs in the right place (relatively moist air) for the right reason (convergence zone). Moreover, $\geq 85 \%$ of the nocturnal precipitation is associated with convergence lines, which constitutes $>33 \%$ of the total (day+night) DJF rainfall and hence provides an important component to the climatological mean. Overall, despite the errors in the daytime convection known to occur in ACCESS1.0 (Ackerley et al. 2014, 2015; Brown et al. 2010), the processes driving nocturnal precipitation are simulated well. The next section investigates whether the same convergence zone-precipitation relationship exists in other GCMs run in climate mode with grid spacing $\sim 100+\mathrm{km}$, or whether it is idiosyncratic to ACCESS1.0 (and the MetUM).

\section{CMIP assessment}

Previous work by Ackerley et al. (2015) shows that a selection of GCMs, from the CMIP5 archive, produce the correct climatological diurnal cycle in the $925 \mathrm{hPa}$ circulation over northwest Australia. The same 9 models from Ackerley et al. (2015) (see Table 1) are now considered here to evaluate whether the convergence-driven nocturnal precipitation is an idiosyncratic feature of ACCESS1.0 or is a process that is common across GCMs. For brevity, the climatological diurnal cycle (discussed in detail in Ackerley et al. 2015) and individual case studies are not discussed in this section. Instead, the focus is on identifying whether convergence lines typically form overnight in this region (north-west Australia) and, that overnight precipitation is predominantly associated with such convergence zones. If 
the models are predominantly producing precipitation associated

with convergence zones overnight (as shown for ACCESS1.0 in

Section 5), then the processes causing that rainfall are likely to be correct.

The results from running the convergence-precipitation detection algorithm are plotted in Figure 12. The first important point to note is that the higher resolution models (e.g. BCCCSM1-1-m and MRI-CGCM3, see Table 1) simulate a lower frequency of convergence lines per grid point than the lower resolution models (e.g. BCC-CSM1-1 and IPSL-CM5A-LR, see Table 1). This is consistent with the analysis of the Par12k simulation, which had fewer detections (per grid point) than ACCESS1.0 given there were more grid points that convergence zones could develop on at any given instance. Nevertheless, convergence lines are detected $\gtrsim 25 \%$ of the time over northwest Australia at 2000 AWST (Figure 12, column 1), which is consistent with the location of the highest climatological mean convergence (see Figure 6 in Ackerley et al. 2015) and shows that the models represent the formation of nocturnal convergence zones (as in ACCESS1.0).

Regarding precipitation ( \pm 3 hr 2000 AWST, Figure 12, column 2) in all models, $\gtrsim 75 \%$ of the precipitation can be attributed to a convergence zone. Therefore, the CMIP5 models (presented in Figure 12 and Table 1) require some form of dynamical forcing in order to produce nocturnal rainfall (as is also the case in ACCESS1.0 and Par12k).

By 0200 AWST, the number of convergence zones detected decreases relative to 2000 AWST (compare Figure 12 column 3 with column 1), which is consistent with the simulated reductions in the climatological mean convergence in the same CMIP5 models (see Figure 6 in Ackerley et al. 2015) and also ACCESS1.0 (Figure 2(1)). Despite there being fewer detected convergence lines, $\geq 75 \%$ of the precipitation at 0200 is associated with such lines (Figure 12, fourth column).

Overall, $\gtrsim 75 \%$ of the precipitation that occurs overnight in GCMs can be attributed to the presence of a convergence zone. Therefore, the GCMs appear to be capable of simulating overnight precipitation for the correct reasons (i.e. dynamically forced from the formation of convergence lines).

\section{Final summation and conclusions}

The aims of this study are to identify how the northwest Australian heat low is responsible for causing nocturnal precipitation and, whether the same process is represented in a selection of GCMs. While our results are consistent with composites from past studies (Berry et al. 2011; Ackerley et al. 2014, 2015), we show that on any given day precipitation is focused on narrow, linear convergence zones, which give the appearance of a broad area of convergence and rainfall when aggregated over multiple days. Thus, in order to summarise the main results of this work, the "typical" sequence of events (based on the 6-hourly analyses in Sections 3-5) leading to nocturnal precipitation are presented as a schematic (Figure 13).

An intrusion of relatively moist tropical air (blue shading) is advected into the periphery of the relatively dry, continental heat low circulation (amber shading) with little mixing between the two air masses (Figure 13(a)). Insolation-driven surface heating during the day (Figure 13(b)) initiates convection, which increases the low-level drag and decreases the humidity. Moist convection may be initiated in the tropical air ("cloud shapes" in Figure 13(b)). After sunset (Figure 13(c)), low level frictional drag diminishes as the nocturnal stable layer forms and the flow accelerates towards the low centre. Convergence zones (dashed lines, Figure 13(c)) form within the continental air (amber shading) but produce no precipitation. Air parcels accelerating towards the low centre in the relatively moist (tropical) air mass may encounter the relatively dry (continental) air mass and be forced to ascend at the boundary (dryline). The forced ascent then results in condensation and precipitation. The flow then turns anticyclonically over time but the dryline and precipitation may persist into the night (Figure 13(d)). Overall, the presence of a heat low is not sufficient to initiate nocturnal rainfall nor is the presence of the tropical moisture intrusion but it is the boundary between the two air masses that becomes the focus for precipitation.

The sequence of events associated with the high-resolution model (Par12k, Figures 13(e)-(h)) are slightly different to those presented for the real world. The first difference is that convective precipitation is triggered too early in the day (Figure 13(e)); however, this is ubiquitous in models with parametrized 


\section{AWST}
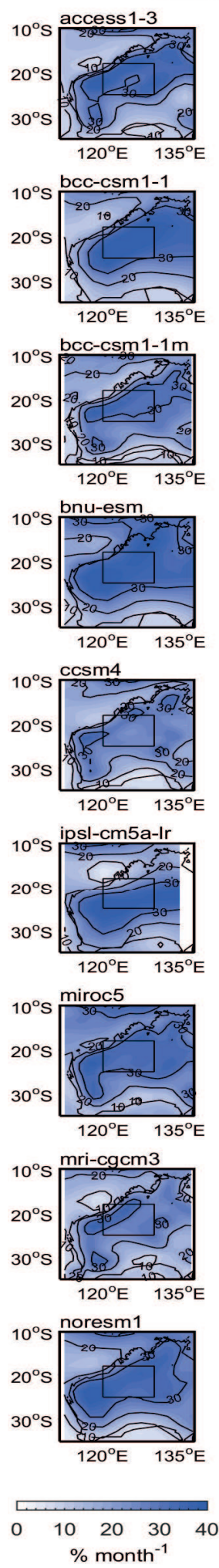
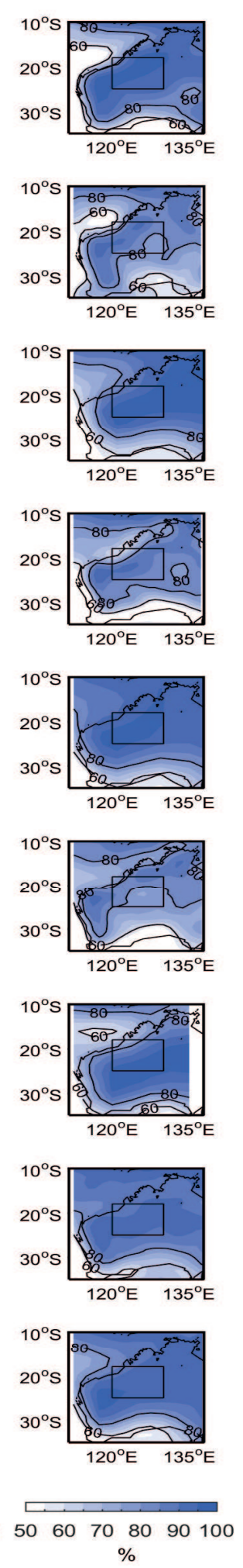

\section{AWST}
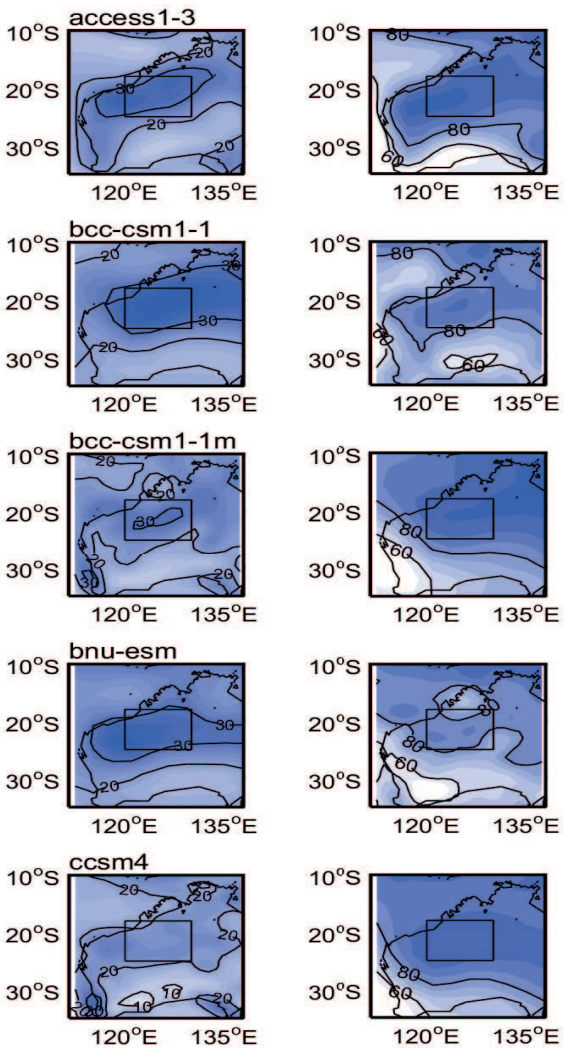

$10^{\circ} \mathrm{S}$ ipsl-cm5a-Ir
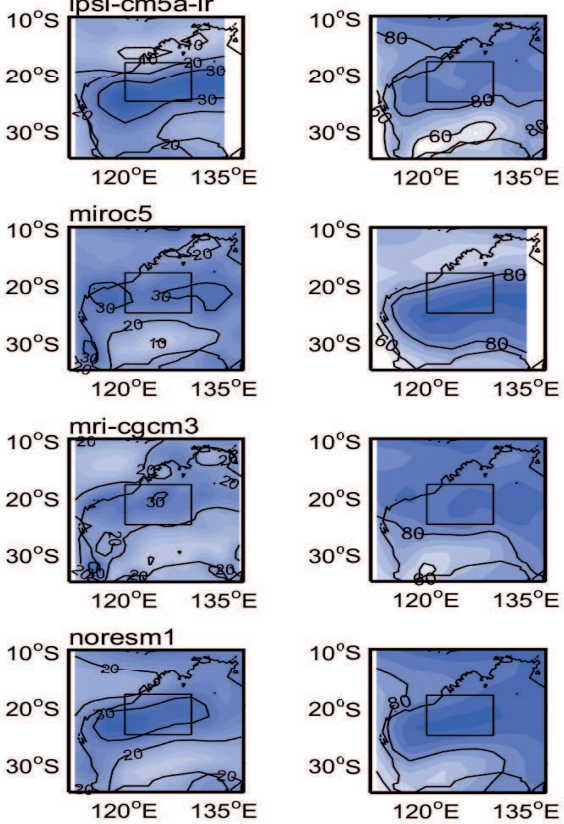

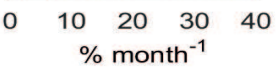

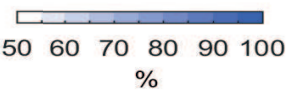

Figure 12. The fractional occurrence of convergence lines at a model grid point (\% month ${ }^{-1}$ ) at 2000 AWST (from left to right, column 1 ) and the percentage of rainfall associated with convergence lines $\pm 3 \mathrm{hr}$ of 2000 AWST (\%, column 2 ) for each model given in Table 1 (consecutive rows and ordered alphabetically). The convergence line occurrence (column 3) and rainfall associated with convergence lines (column 4) for each model (rows) are also plotted for 0200 AWST. Model data taken over 29 DJFs from 1979/80-2007/08.

convection as described in Ackerley et al. (2015); Birch et al. (2015); Brown et al. (2010); Dai (2006); Stratton and Stirling (2012); Yang and Slingo (2001), and also Sections 4 and 5. More importantly, the Par12k model does not produce precipitation in the relatively dry continental air (as in the real world) therefore the presence of a heat low circulation alone is not sufficient to trigger precipitation. Furthermore, Par12k also simulates the daytime flow weakening and humidity reduction associated with turbulent mixing (Figure 13(f)). After sunset, convection from insolation-driven surface heating stops and the flow accelerates 
(a) 0800 AWST: Obs.

(b) 1400 AWST: Obs.

(c) 2000 AWST: Obs.

(d) 0200 AWST: Obs.

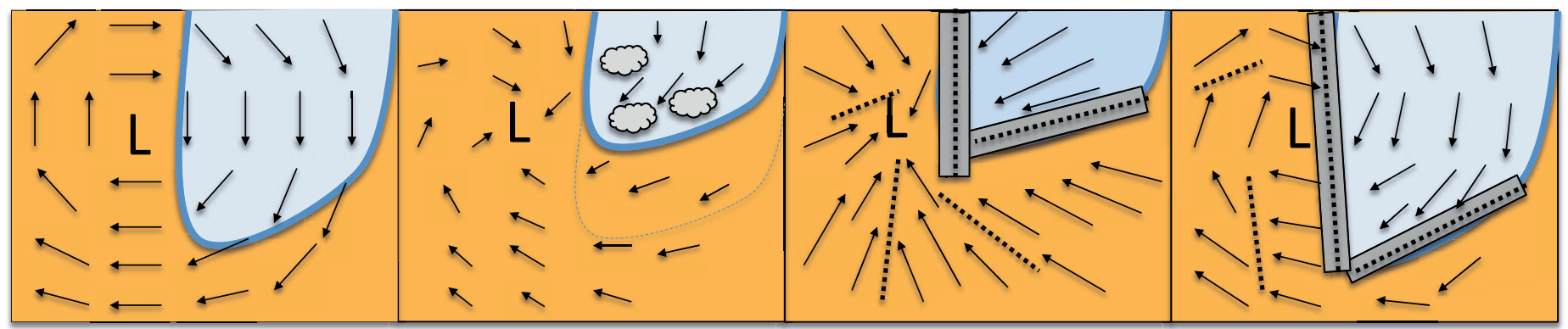

(e) 0800 AWST: Par12k

(f) 1400 AWST: Par12k

(g) 2000 AWST: Par12k

(h) 0200 AWST: Par12k

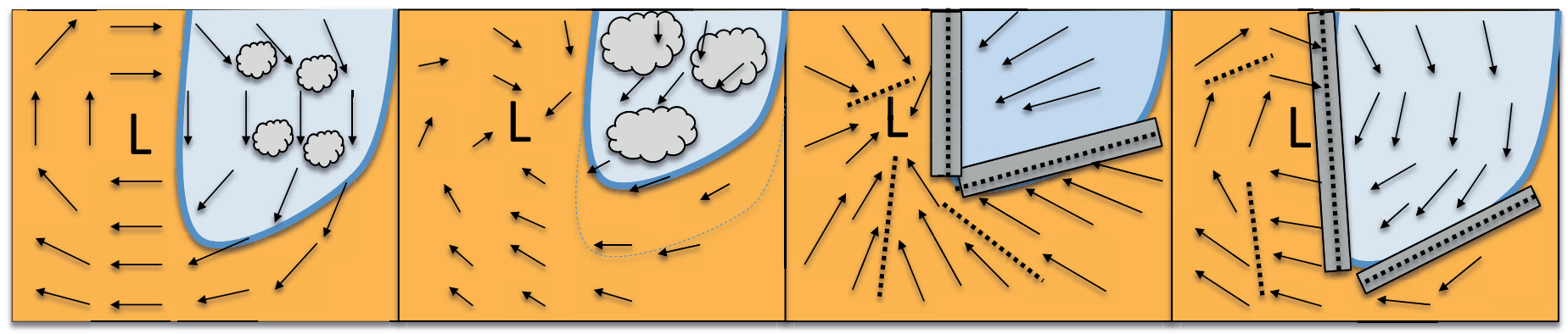

$\begin{array}{ll}\text { (i) } 0800 \text { AWST: ACCESS1.0 } & \text { (j) } 1400 \text { AWST: ACCESS1.0 }\end{array}$

(k) 2000 AWST: ACCESS1.0

(I) 0200 AWST: ACCESS1.0

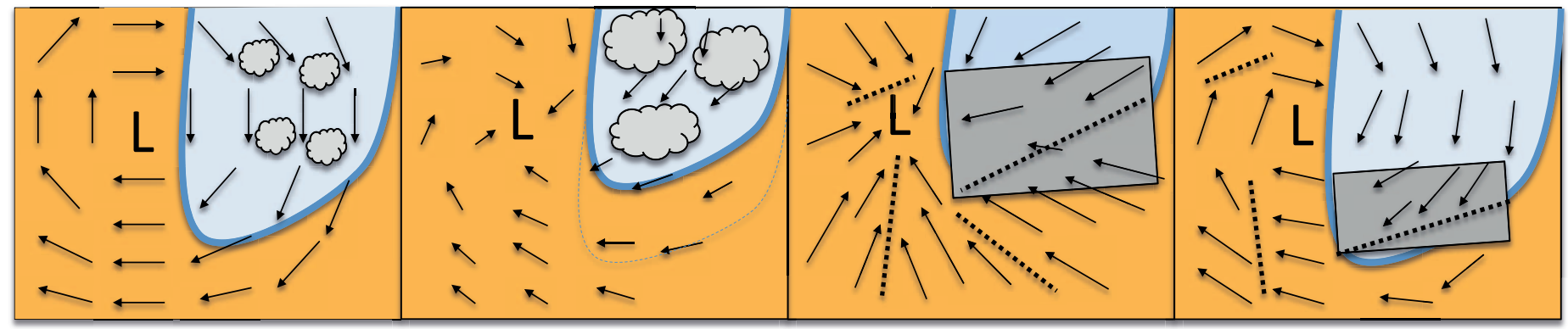

Figure 13. Schematic diagram illustrating the diurnal cycle of the low-level ( $925 \mathrm{hPa}$ ) circulation, moisture and convection/rainfall for (a-d) the observed real world (Obs.), (e-h) the $12 \mathrm{~km}$ grid spaced MetUM with parameterized convection (Par12k), and (i-1) ACCESS1.0. Arrows indicate the strength and direction of the flow, blue (amber) shading denotes moist tropical (dry continental) air, the separation of the two air masses is the dryline (thick blue line), dashed lines indicate convergence zones, grey "cloud shapes" indicate isolated convection and solid grey boxes organised convection and rainfall along convergence zones (dashed lines only indicate convergence and no precipitation). L denotes the centre of the heat low circulation. Times are given in Australian Western Standard Time (AWST, UTC+8). The blue dashed lines at 1400 AWST indicate the region where the moist air has been mixed sufficiently (relative to 0800 AWST) to be considered dry, continental air.

towards the local heat low centre (Figure 13(g)). Convergence zones and precipitation (where there is sufficient moisture present) form along the dryline. Therefore, despite the misrepresentation of daytime convection, the Par12k model simulates nocturnal precipitation for the correct physical reasons. As in the real world, the drylines may persist into the night along with the associated precipitation (Figure 13(h).

A similar sequence of events to Par12k also leads to nocturnal precipitation in the ACCESS1.0 simulations. Convection is triggered prematurely (Figure 13(i)); however, the daytime reduction in the low-level flow strength and humidity are represented (Figure 13(j)). Overnight, the low-level, turbulenceinduced drag diminishes and air parcels accelerate down the pressure gradient, which results in the development of convergence zones and precipitation (Figure 13(k) and (l)). The convergence zones in ACCESS1.0 cover a larger aerial extent that those in Par12k (see Sections 4 and 5); however, precipitation only occurs where there is sufficient moisture present (i.e. not within the drier continental air). Thus, the processes leading to the formation of nocturnal precipitation are simulated at both low (ACCESS1.0) and high (Par12k) resolution.

Although the schematic (Figure 13) relates to the formation of precipitation in the vicinity of a dryline, other convergence features (for example sea breeze fronts) may also be strengthened by the diurnal cycle in the low-level flow. Hence, the fraction of nocturnal precipitation that can be attributed to any convergence line is assessed for ERA-Interim/CMORPH, Par12k and ACCESS1.0. Typically, $>75 \%$ of overnight rainfall can be 
attributed to the presence of a convergence zone for ERAInterim/CMORPH, Par12k and ACCESS1.0 (see Figures 3, 6 and 9, respectively). Moreover, a similar percentage (i.e. $>75 \%$ ) of nocturnal precipitation is also attributed to convergence zones in the selection of CMIP5 GCMs listed in Table 1 (see Figure 12). Given that Ackerley et al. (2015) show the climatological convergence around the heat low strengthens overnight and corresponds with increased precipitation for those same models (listed in Table 1), it is likely that they are also representing the same process described above.

Overall, the processes that lead to the formation of nocturnal precipitation over north-west Australia are represented in GCMs with parametrized convection. Nonetheless, the models only produce approximately $20-50 \%$ of the seasonal (DJF) rainfall overnight whereas the contribution is $>50 \%$ in the real world. The smaller proportion of overnight rainfall (relative to the overall total) in the models may be simply due to the large proportion of daytime precipitation (i.e. the nocturnal contribution is correct). Nonetheless, the lower proportion of nighttime rain may also be partially due to the removal of atmospheric instability by the daytime parametrized convection, which causes the nocturnal atmosphere to be more stable (above the nocturnal boundary layer). Thus, improving the representation of daytime convection may lead to an increase in the contribution of the dynamicallydriven nocturnal precipitation. An area of future work therefore, would be to run Numerical Weather Prediction-type (i.e. run the model in "forecast mode") simulations of specific case studies identified over north-west Australia (and other areas of the globe) at the various model resolutions described in this paper. The resolution dependence and sequence of events described in this paper could then be fully confirmed and the limitations of the models verified.

Despite the nocturnal rainfall contribution to the seasonal total being too low, the correct representation of the physical process that cause it is encouraging and is important for two reasons:

(i) It may be possible to quantify how this process may change under global warming and;

(ii) It may be applicable to other regions of the world that have a summertime heat low circulation (e.g. North Africa and specifically the nocturnal "Monsoon Surge",
Parker etal. 2005) or increased nocturnal convergence from the reorganisation of the low-level flow (e.g. the midwest of the United States of America, Dai et al. 1999)

For (i) above, the analysis would simply involve re-running the convergence line detection and precipitation attribution method described in this study. From such an analysis, the frequency of convergence line formation and the amount of precipitation associated with them could be diagnosed directly. For (ii) above, the first step would be to identify whether the diurnal cycle of the flow is represented correctly and then to identify whether any nocturnal precipitation is produced as a result of the reorganisation (perhaps using case studies as presented here). Then the convergence line algorithm can be used to evaluate the contribution of convergence zones to the nocturnal precipitation. Finally, the process can be repeated on the future climate change simulations to evaluate how the processes may (or may not) change under global warming. Given the poor representation of parametrized convection in GCMs during the daytime (see Ackerley et al. 2015; Birch et al. 2015; Brown et al. 2010; Dai 2006; Stratton and Stirling 2012; Yang and Slingo 2001, and also Sections 4 and 5), an analysis of larger-scale, dynamically driven rainfall generation processes in the tropics and sub-tropics may yield useful information of how precipitation may (or may not) change in the future.

\section{Acknowledgements}

This project was funded by the Australian Research Council Centre of Excellence for Climate System Science (CE11000128). ACCESS1.0 simulations and data storage were undertaken at the Australian National Computational Infrastructure (NCI) National Facility, which is supported by the Australian Government. Data from CMIP5 were made available through NCI and the Earth System Grid Federation (2013-2014). ERA-Interim and YOTC data were provided by the ECMWF and the CMORPH rainfall data were provided by UCAR at https://climatedataguide.ucar.edu/climate-data/cmorph-cpcmorphing-technique-high-resolution-precipitation-60s-60n.

The authors gratefully thank Malcolm Roberts for the Par12k simulation data, which was produced on the Met Office supercomputer with support from the Joint U.K. BEIS/DEFRA 
Met Office Hadley Centre Climate Programme (GA01101), and distributed via the JASMIN superdata cluster (Lawrence et al. 2012) managed by the Science and Technology Facilities Council Scientific Computing Department (SCD) on behalf of the Centre for Environmental Data Archival.

\section{References}

Ackerley D, Berry G, Jakob C, Reeder MJ. 2014. The roles of diurnal forcing and large-scale moisture transport for initiating rain over north-west Australia in a GCM. Quart. J. Roy. Meteor. Soc. 140: 2515-2526.

Ackerley D, Berry G, Jakob C, Reeder MJ, Schwendike J. 2015. Summertime precipitation over northern Australia in AMIP simulations from CMIP5. Quart. J. Roy. Meteor. Soc. 141: 1753-1768.

Allcock MM, Ackerley D. 2016. Representing the australian heat low in a gcm using different surface and cloud schemes. Advances in Meteorology (9702607), doi:10.1155/2016/9702607.

Arnup SJ, Reeder MJ. 2007. The diurnal and seasonal variation of the northern Australian dryline. Mon. Wea. Rev. 135: 2995-3008.

Arnup SJ, Reeder MJ. 2009. The structure and evolution of the northern Australian dryline. Aust. Meteorol. Ocean. Journal 58: 215-231.

Bentsen M, Bethke I, Debernard JB, Iversen T, Kirkevåg A, Seland $\varnothing$, Drange H, Roelandt C, Seierstad IA, Hoose C, Kristjánsson JE. 2013. The Norwegian Earth System Model, NorESM1-M part 1: Description and basic evaluation of the physical climate. Geosci. Model Dev. 6(3): 687-720, doi:10.5194/gmd-6-687-2013, URL http://www.geosci-model-dev.net/6/687/2013/.

Berry G, Reeder MJ. 2014. Objective identification of the intertropical convergence zone: Climatology and trends from the era-interim. J. Climate 27: 1894-1909.

Berry G, Reeder MJ, Jakob C. 2011. Physical mechanisms regulating summertime rainfall over northwestern Australia. J. Climate 24: 37053717.

Betts AK, Jakob C. 2002a. Evaluation of the diurnal cycle of precipitation, surface thermodynamics, and surface fluxes in the ECMWF model using LBA data. J. Geophys. Res. 107(D20): doi:10.1029/2001JD000 427.

Betts AK, Jakob C. 2002b. Study of diurnal cycle of convective precipitation over Amazonia using a single column model. J. Geophys. Res. 107(D23): doi:10.1029/2002JD002 264.

Bi D, Dix M, Marsland SJ, O’Farrell S, Rashid HA, Uotila P, Hirst AC, Golebiewski EKM, Sullivan A, Yan H, Hannah N, Franklin C, Sun Z, Vohralik P, Watterson I, Zhou Z, Fiedler R, Collier M, Ma Y, Noonan J, Stevens L, Uhe P, Zhu H, Griffies SM, Hill R, Harris C, Puri K. 2013. The ACCESS coupled model: description, control climate and evaluation. Aust. Meteorol. Ocean. Journal 63: 41-64.

Birch CE, Roberts MJ, Garcia-Carreras L, Ackerley D, Reeder MJ, Lock AP, Schiemann R. 2015. Sea-breeze dynamics and convection initiation:
The influence of convective parameterization in weather and climate model biases. J. Climate 28: 8093-8108.

Brown JR, Jakob C, Haynes JM. 2010. An evaluation of rainfall frequency and intensity over the Australian region in a global climate model. J. Climate 23: 6504-6525.

Catto JL, Jakob C, Berry G, Nicholls N. 2012. Relating global precipitation to atmospheric fronts. Geophys. Res. Lett. 39. L10805.

Dai A. 2006. Precipitation characteristics in eighteen coupled climate models. J. Climate 19: 4605-4630.

Dai A, Giorgi F, Trenberth KE. 1999. Observed and model-simulated diurnal cycles of precipitation over the contiguous United States. J. Geophys. Res. 104(D6): 6377-6402.

Dai A, Lin X, Hsu KL. 2007. The frequency, intensity, and the diurnal cycle of precipitation in surface and satellite observations over low- and midlatitudes. Clim. Dynam. 29: 727-744.

Dee DP, Uppala SM, Simmons AJ, Berrisford P, Poli P, Kobayashi S, Andrae U, Balmaseda MA, Balsamo G, Bauer P, Bechtold P, Beljaars ACM, van de Berg L, Bidlot J, Bormann N, Delsol C, Dragani R, Fuentes M, Geer AJ, Haimberger L, Healy SB, Hersbach H, Holm EV, Isaksen L, Kallberg P, Kohler M, Matricardi M, McNally AP, Monge-Sanz BM, Morcrette JJ, Park BK, de Rosnay CPP, Tavolato C, Thepaut JN, Vitart F. 2011. The ERAInterim reanalysis: configuration and performance of the data assimilation system. Quart. J. Roy. Meteor. Soc. 137: 553-597.

Deslandes R, Reeder MJ, Mills G. 1998. Synoptic analyses of a subtropical cold front observed during the 1991 Central Australian Fronts Experiment. Aust. Met. Mag. 48: 87-110.

Dirmeyer PA, Cash BA, Kinter III JL, Jung T, Marx L, Satoh M, Stan C, Tomita H, Towers P, Wedi N, Achuthavarier D, Adams JM, Altshuler EL, Huang B, Jin EK, Manganello J. 2012. Simulating the diurnal cycle of rainfall in global climate models: resolution versus parameterization. Clim. Dynam. 39: 399-418.

Donlon CJ, Martin M, Stark JD, Roberts-Jones J, Fiedler E, Wimmer W. 2012. The operational sea surface temperature and sea ice analysis (ostia) system. Remote Sens. Environ. 116: 140-158.

Dufresne JL, Foujols MA, Denvil S, Caubel A, Marti O, Aumont O, Balkanski Y, Bekki S, Bellenger H, Benshila R, Bony S, Bopp L, Braconnot P, Brockmann P, Cadule P, Cheruy F, Codron F, Cozic A, Cugnet D, Noblet N, Duvel JP, Eth C, Fairhead L, Fichefet T, Flavoni S, Friedlingstein P, Grandpeix JY, Guez L, Guilyardi E, Hauglustaine D, Hourdin F, Idelkadi A, Ghattas J, Joussaume S, Kageyama M, Krinner G, Labetoulle S, Lahellec A, Lefebvre MP, Lefevre F, Levy C, Li Z, Lloyd J, Lott F, Madec G, Mancip M, Marchand M, Masson S, Meurdesoif Y, Mignot J, Musat I, Parouty S, Polcher J, Rio C, Schulz M, Swingedouw D, Szopa S, Talandier C, Terray P, Viovy N, Vuichard N. 2013. Climate change projections using the IPSL-CM5 Earth System Model: from CMIP3 to CMIP5. Clim. Dynam. 40(9-10): 2123-2165, doi:10.1007/s00382-012-1636-1, URL http://dx.doi.org/10.1007/s00382-012-1636-1. 
Garcia-Carreras L, Marsham JH, Parker DJ, Bain CL, Milton S, Saci A, Salah-

Ferroudj M, Ouchene B, Washington R. 2013. The impact of convective cold pool outflows on model biases in the Sahara. Geophys. Res. Lett. 40: $1647-1652$.

Gates WL. 1992. AMIP: The atmospheric model intercomparison project. Bull. Amer. Meteor. Soc. 73: 1962-1970.

Gates WL, Boyle JS, Covey C, Dease CG, Doutriaux CM, Drach RS, Florino M, Gleckler PJ, Hnilo JJ, Marlais SM, Phillips TJ, Potter GL, Santer BD, Sperber KR, Taylor KE, Williams DN. 1999. An overview of the results of the atmospheric model intercomparison project (AMIP I). Bull. Amer. Meteor. Soc. 80: 29-55.

Gent PR, Danabasoglu G, Donner LJ, Holland MM, Hunke EC, Jayne SR, Lawrence DM, Neale RB, Rasch PJ, Vertenstein M, Worley PH, Yang ZL, Zhang M. 2011. The Community Climate System Model Version 4. J. Climate 24: 4973-4991.

Gregory D, Rowntree PR. 1990. A mass flux convection scheme with representation of cloud ensemble characteristics and stability-dependent closure. Mon. Wea. Rev. 118: 1483-1506.

Hewitt HT, Copsey D, Culverwell ID, Harriss CM, Hill RSR, Keen AB, McLaren AJ, Hunke EC. 2011. Design and implementation of the infrastructure of HadGEM3: the next-generation Met Office climate modelling system. Geosci. Model Dev. 4: 223-253.

Ji D, Wang L, Feng J, Wu Q, Cheng H, Zhang Q, Yang J, Dong W, Dai Y, Gong D, Zhang RH, Wang X, Liu J, Moore JC, Chen D, Zhou M. 2014. Description and basic evaluation of BNU-ESM Version 1. Geosci. Model Dev. Discuss. 7: 1601-1647.

Joyce RJ, Janowiak JE, Arkin PA, Xie P. 2004. CMORPH: A method that produces global precipitation estimates from microwave and infrared data at high spatial and temporal resolution. J. Hydrometeor. 5: 487-503.

Kowalczyk EA, Stevens L, Law RM, Dix M, Wang YP, Harman IN, Haynes K, Srbinovsky J, Pak B, Ziehn T. 2013. The land surface model component of access: description and impact on simulated surface climatology. Aust. Meteorol. Ocean. Journal 63: 65-82.

Lavender SL. 2017. A climatology of australian heat low events. Int. J. Climatol. 37: 534-539.

Martin GM, Bellouin N, Collins WJ, Culverwell ID, Halloran PR, Hardiman SC, Hinton TJ, Jones CD, McDonald RE, McLaren AJ, O'Connor FM, Roberts MJ, Rodriguez JM, Woodward S, Best MJ, Brooks ME, Brown AR, Butchart N, Dearden C, Derbyshire SH, Dharssi I, Doutriaux-Boucher M, Edwards JM, Falloon PD, Gedney N, Gray LJ, Hewitt HT, Hobson M, Huddleston MR, Hughes J, Ineson S, Ingram WJ, James PM, Johns TC, Johnson CE, Jones A, Jones CP, Joshi MM, Keen AB, Liddicoat S, Lock AP, Maidens AV, Manners JC, Milton SF, Rae JGL, Ridley JK, Sellar A, Senior CA, Totterdell IJ, Verhoef A, Vidale PL, Wiltshire A. 2011. The HadGEM2 family of Met Office Unified Model climate configurations. Geosci. Model Dev. 4(3): 723-757, doi:10.5194/gmd-4-723-2011, URL http://www.geosci-model-dev - net/4/723/2011/.
Moncrieff MW, Waliser DE, Miller MJ, Shapiro MA, Asrar GR, Caughey J. 2012. Multiscale convective organisation and the YOTC virtual global field campaign. Bull. Amer. Meteor. Soc. 93: 1171-1187.

Neale R, Slingo J. 2003. The Maritime Continent and its role in the global climate: A GCM Study. J. Climate 16: 834-848.

Parker DJ, Burton RR, Diongue-Niang A, Felton M, Taylor CM, Thorncroft CD, Bessemoulin P, Tompkins AM. 2005. The diurnal cycle of the West African monsoon circulation. Quart. J. Roy. Meteor. Soc. 131: 2839-2860.

Racz Z, Smith RK. 1999. The dynamics of heat lows. Quart. J. Roy. Meteor. Soc. 125: 225-252.

Roberts A, Marsham J, Knippertz P. 2015. Disagreements in low-level moisture between (re)analyses over summertime West Africa. Mon. Wea. Rev. 143: 1193-1211.

Spengler T, Reeder MJ, Smith RK. 2005. The dynamics of heat lows in simple background flows. Quart. J. Roy. Meteor. Soc. 19: 3147-3165.

Spengler T, Smith RK. 2008. The dynamics of heat lows over flat terrain. Quart. J. Roy. Meteor. Soc. 134: 2157-2172.

Stratton RA, Stirling AJ. 2012. Improving the diurnal cycle of convection in GCMs. Quart. J. Roy. Meteor. Soc. 138: 1121-1134.

Taylor K, Stouffer RJ, Meehl GA. 2012. An overview of CMIP5 and the experiment design. Bull. Amer. Meteor. Soc. 93: 485-498.

Taylor KE, Williamson D, Zwiers F. 2000. The sea surface temperature and sea-ice concentration boundary conditions of AMIP II simulations. PCMDI Rep. 60.

Vellinga M, Roberts M, Vidale PL, Mizielinski MS, Demory ME, Schiemann R, Strachan J, Bain C. 2016. Sahel decadal rainfall variability and the role of model horizontal resolution. Geophys. Res. Lett. 43(1): 326-333, doi: 10.1002/2015GL066690. 2015GL066690.

Walters DN, Best MJ, Bushell AC, Copsey D, Edwards JM, Falloon PD, Harris CM, Lock AP, Manners JC, Morcrette CJ, Roberts MJ, Stratton RA, Webster S, Wilkinson JM, Willett MR, Boutle IA, Earnshaw PD, Hill PG, MacLachlan C, Martin GM, Moufouma-Okia W, Palmer MD, Petch JC, Rooney GG, Scaife AA, Williams KD. 2011. The Met Office Unified Model Global Atmosphere 3.0/3.1 and JULES Global Land 3.0/3.1 configurations. Geosci. Model Dev. 4: 919-941.

Walters DN, Williams KD, Boutle IA, Bushell AC, Edwards JM, Field PR, Lock AP, Morcrette CJ, Stratton RA, Wilkinson JM, Willett MR, Bellouin N, Bodas-Salcedo A, Brooks ME, Copsey D, Earnshaw PD, Hardiman SC, Harris CM, Levine RC, MacLachlan C, Manners JC, Martin GM, Milton SF, Palmer MD, Roberts MJ, Rodríguez JM, Tennant WJ, Vidale PL. 2014. The met office unified model global atmosphere 4.0 and jules global land 4.0 configurations. Geosci. Model Dev. 7: 361-386.

Watanabe M, Suzuki T, O'Ishi R, Komuro Y, Watanabe S, Emori S, Takemura T, Chikira M, Ogura T, Sekiguchi M, Takata K, Yamazaki S, Yokohata T, Nozawa T, Hasumi H, Tatebe H, Kimoto M. 2010. Improved climate simulation by MIROC5: Mean states, variability and climate sensitivity. $J$. Climate 23: 6312-6335. 
Weller E, Shelton K, Reeder MJ, Jakob C. 2017. Precipitation associated with convergence lines. J. Climate doi:10.1175/JCLI-D-16-0535.1.

Wu T, Yu R, Zhang F, Wang Z, Dong M, Wang L, Jin X, Chen D, Li L. 2010. The Beijing Climate Center atmospheric general circulation model: description and its performance for the present-day climate. Clim. Dynam. : 123-147.

Xin XG, Wu TW, Li JL, Wang ZZ, Li WP, Wu FH. 2013. How well dows the BCC-CSM1.1 reproduce the 20th century climate change over China? Atmospheric and Oceanic Science Letters 6(1): 21-26.

Yang GY, Slingo J. 2001. The diurnal cycle in the tropics. Mon. Wea. Rev. 129: 784-801.

Yang S, Smith EA. 2006. Mechanisms for diurnal variability of global tropical rainfall observed from TRMM. J. Climate 19: 5190-5226.

Yukimoto S, Adachi Y, Hosaka M, Sakami T, Yoshimura H, Hirabara M, Tanaka TY, Shindo E, Tsujino H, Deushi M, Mizuta R, Yabu S, Obata A, Nakano H, Koshiro T, Ose T, Kitoh A. 2012. A new global climate model of the Meteorological Research Institute: MRI-CGCM3-model description and basic performance. J. Meteor. Soc. Japan 90A: 23-64. 